\title{
Characterization Report on Sand, Slag, and Crucible Residues and on Fluoride Residues
}

by

A. M. Murray

Westinghouse Savannah River Company

Savannah River Site

Aiken, South Carolina 29808

DOE Contract No. DE-AC09-96SR18500

This paper was prepared in connection with work done under the above contract number with the U.S.

Department of Energy. By acceptance of this paper, the publisher and/or recipient acknowledges the U.S. Government's right to retain a nonexclusive, royalty-free license in and to any copyright covering this paper, along with the right to reproduce and to authorize others to reproduce all or part of the copyrighted paper. 


\section{DISCLAIMER}

This report was prepared as an account of work sponsored by an agency of the United States Government. Neither the United States Government nor any agency thereof, nor any of their employees, makes any warranty, express or implied, or assumes any legal liability or responsibility for the accuracy, completeness, or usefulness of any information, apparatus, product, or process disclosed, or represents that its use would not infringe privately owned rights. Reference herein to any specific commercial product, process, or service by trade name, trademark, manufacturer, or otherwise does not necessarily constitute or imply its endorsement, recommendation, or favoring by the United States Government or any agency thereof. The views and opinions of authors expressed herein do not necessarily state or reflect those of the United States Government or any agency thereof.

This report has been reproduced directly from the best available copy.

Available to DOE and DOE contractors from the Office of Scientific and Technical Information, P. O. Box 62, Oak Ridge, TN 37831; prices available from (423) 576-8401.

Available to the public from the National Technical Information Service, U. S. Department of Commerce, 5285 Port Royal Road, Springfield, VA 22161. 


\section{DISCLAIMER}

Portions of this document may be illegible in electronic image products. Images are produced from the best available original document. 
WSRC-TR- $98-00311$

RECORDS ADMINISTRATION

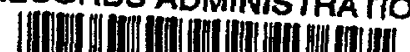

R0089134

\title{
Characterization Report \\ On \\ Sand, Slag, and Crucible Residues \\ And On \\ Fluoride Residues
}

\begin{abstract}
Alice M. Murray
Chemical and Hydrogen Technology Section

Savannah River Technology Center

Westinghouse Savannah River Company
\end{abstract}

September 22, 1998

Hintin.

Technical Reviewer

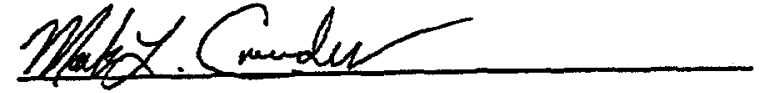

M. L. Crowder

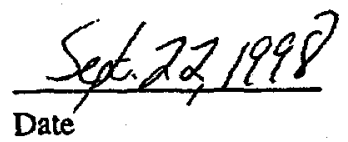




\section{Executive Summary}

This paper reports on the chemical characterization of the sand, slag, and crucible (SS\&C) residues and the fluoride residues that may be shipped from the Rocky Flats Environmental Technology Site (RFETS) to Savannah River Site (SRS). Extensive use was made of process knowledge and information obtained by the RFETS Solid Residue Characterization Program. Important points in the report are given below.

1. The treatment of the SS\&C material prior to packaging (i.e., pulverization and sieving in an airatmosphere giovebox) should eliminate any pyrophoric belravior as defined by the Department of Transportation in the Code of Federal Regulations.

2. Room temperature oxidation of calcium or plutonium metal is not expected to proceed at a rate that will generate heat in excess of 0.39 watts once the material is placed into the 9975 Package.

3. Oxidation of calcium at temperatures up to $107^{\circ} \mathrm{C}$ is not expected to proceed at a rate that will generate heat in excess of 0.39 watts once the material is placed into the 9975 Package.

4. Calculations of the oxidation of plutonium at temperatures up to $107^{\circ} \mathrm{C}$ indicate that the reaction could proceed at a rate that will generate heat up to 3.5 watts. Those calculations are based on very conservative assumptions: all of the plutonium exists as exposed metal and the water vapor pressure of the adsorbed water is the same as the water vapor pressure of condensed water. No such thermal events were identified in the Differential Thermal Analysis scans from the SS\&C samples.

5. Generation of hydrogen is anticipated from radiolytic and chemical mechanisms. Any hydrogen gas will be available to react with plutonium metal to form plutonium hydride. The reaction is limited by the availability of hydrogen gas. At room temperature the worst gas is a rate based on the calcium/ water vapor reaction. At higher temperatures the worst gas is a rate based on the plutonium/water vapor reaction. The average heat generation rates for those two cases are 5 watts (completed before placing container in 9975 Package) and 0.26 watts.

6. Based on the RFETS Solid Residue Characterization Program, the fluoride heel material may be unsuitable for shipment because of corrosion issues. That material may need to be calcined prior to shipment. 


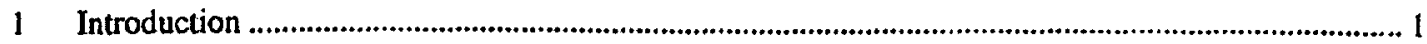

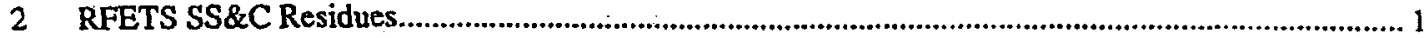

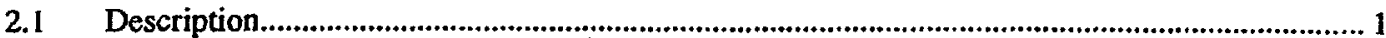

2.2 Results from RFETS Solid Residue Characterization Program ......................................................2 2

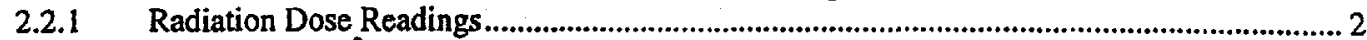

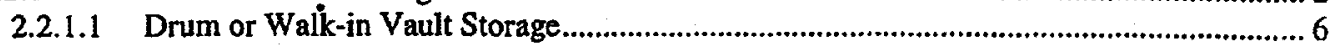

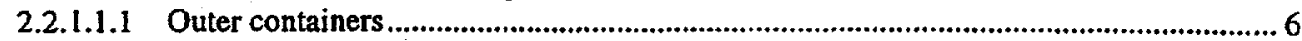

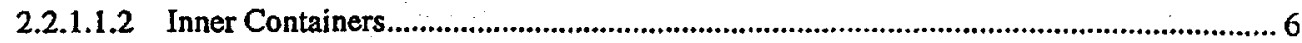

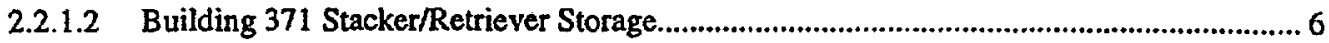

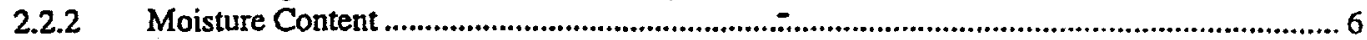

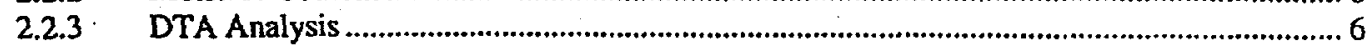

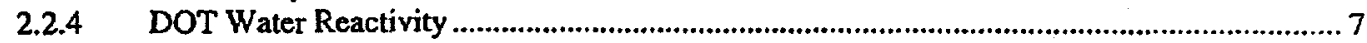

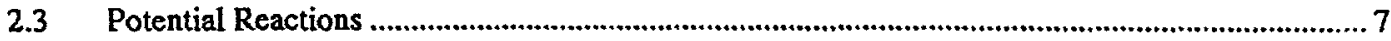

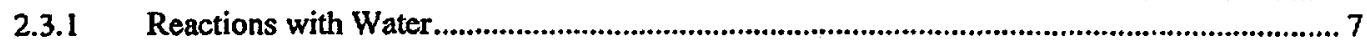

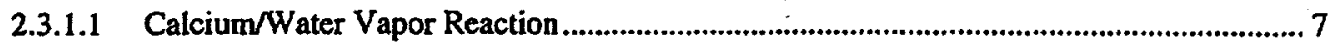

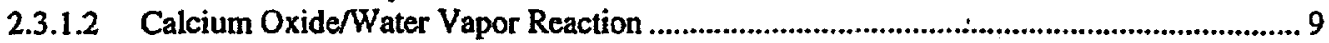

2.3.1.3 Plutonium/Water Vapor Reactions ...................................................................... 10

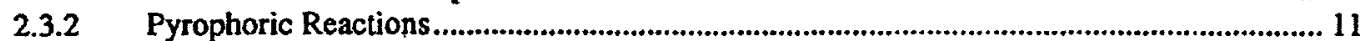

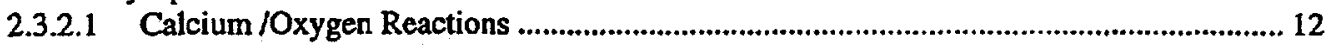

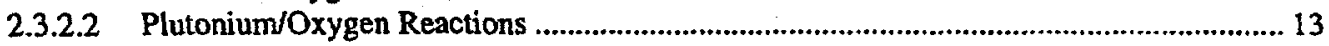

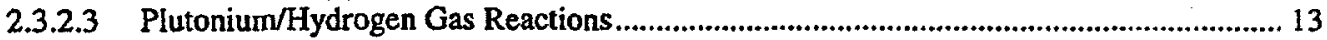

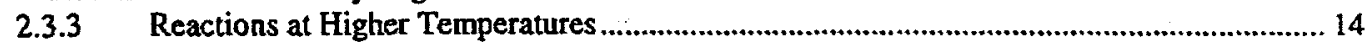

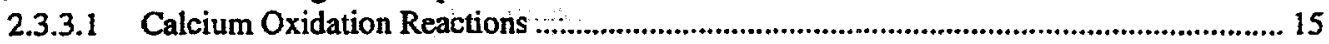

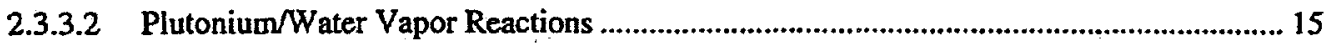

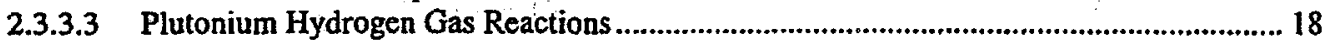

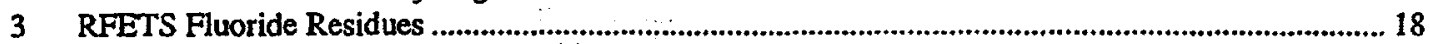

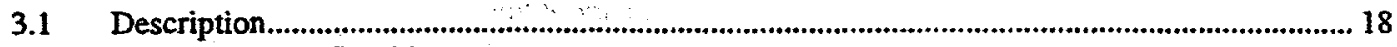

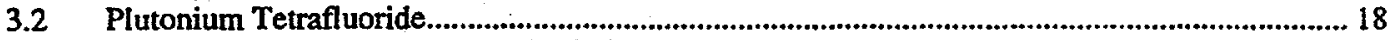

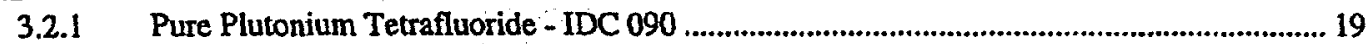

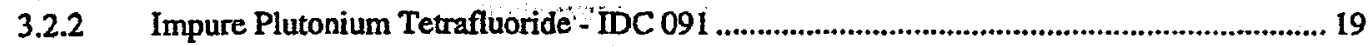

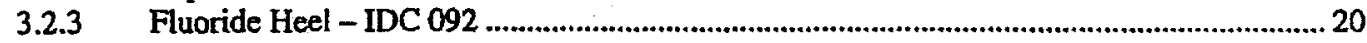

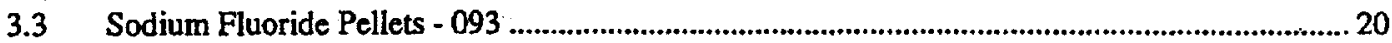

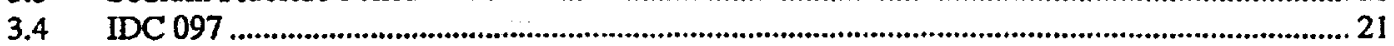

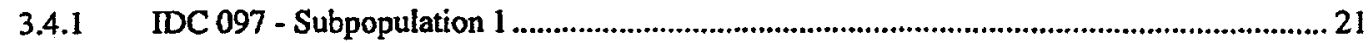

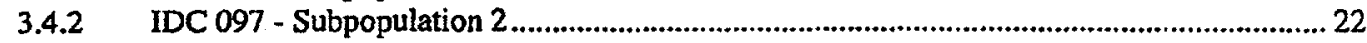

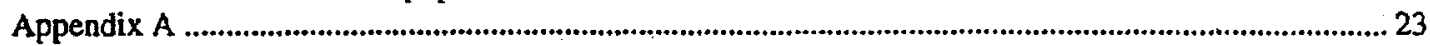

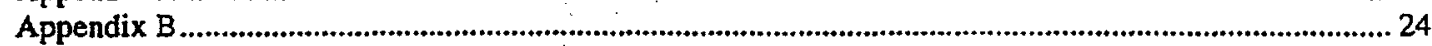

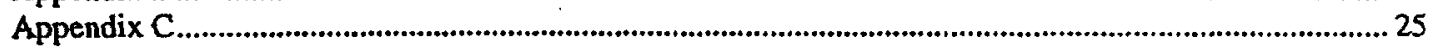

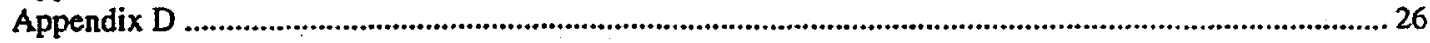

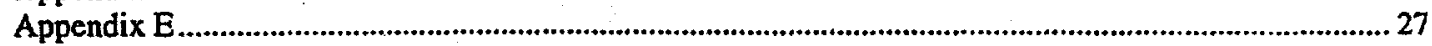

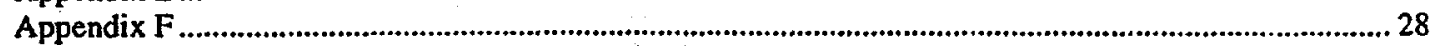

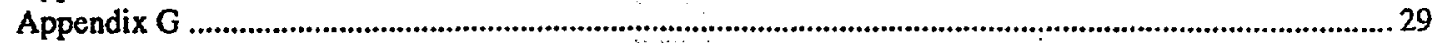

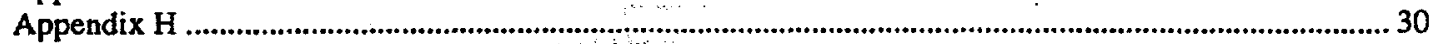

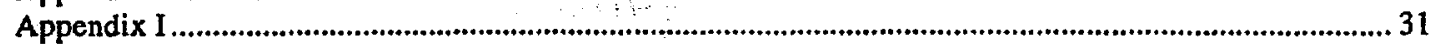


WSRC-TR-98-00311

September 22, 1998

\section{Introduction}

Several residues at the Rocky Flats Environmental Technology Site (RFETS) may be shipped to the Savannah River Site (SRS) for processing to stabilize the plutonium. Those residues can be divided into two groups: the sand, slag, and crucible (SS\&C) residues and the fluoride residues. Initially, Department of Transportation (DOT) Type B 6M containers were going to be used to ship the SS\&C residues that contained less than 20 curies of plutonium, and 9975 Packages were going to be used to ship the remaining SS\&C and fluoride material. However, the current plan is to use the 9975 Package to ship all of the material. The 9975 Package is a Type B, double-containment package that was developed to ship plutonium oxides in quantities greater than 20 curies.

The Safety Analysis Report of Packaging (SARP) for the 9975 Package needs to reviewed and amended, as necessary, to accommodate shipment of the SS\&C and fluoride materials. That review considers several issues including radiation exposure, chemical compatibility and reactions, nuclear criticality safety, and radionuclide isotopic distribution. A good description of the SS\&C and fluoride material is important to any successful SARP review. This report provides a description of those materials based on process knowledge and results from the RFETS Solid Residue Characterization Program. In addition, this report presents the major chemical reactions that could occur during shipment based on the chemical constituents in the material.

\section{RFETS SS\&C Residues}

\subsection{Description}

The SS\&C residues were generated from the calcium reduction of plutonium tetrafluoride, referred to as the bomb reduction process. Plutonium tetrafluoride and calcium were placed in a magnesium oxide crucible along with some initiators such as sodium peroxide. The crucible was packed in sand in a furnace chamber. The furnace chamber was heated and the initiators reacted to boost the reaction temperature. Plutonium metal was produced, and calcium fluoride (the slag) was the main by-product from the process. The crucible and sand were removed from the cooled furnace chamber. The crucible was broken open and the plutonium metal button was retrieved. The remaining contents were sorted into seven different categories as the operators attempted to segregate the sand, slag, and crucible materials. Those categories are referred to by their Item Description Code (IDC) and are as follows:

$$
\begin{aligned}
& \text { IDC } 390 \text { Unpulverized Slag } \\
& \text { IDC } 391 \text { Unpulverized Sand and Crucible } \\
& \text { IDC } 392 \text { Unpulverized Sand, Slag, and Crucible } \\
& \text { IDC } 394 \text { Sand from Button BreakOut } \\
& \text { IDC } 395 \text { Unpulverized Slag and Crucible } \\
& \text { IDC } 396 \text { Pulverized Slag } \\
& \text { IDC } 398 \text { Pulverized Sand, Slag, and Crucible. }
\end{aligned}
$$

The initial material was designated as unpulverized. Pulverization was done to prepare the material for dissolution. Those residues consist primarily of calcium fluoride (slag) and magnesium oxide (from the crucible and sand). Other probable constituents in the SS\&C material are calcium metal, calcium oxide, calcium hydroxide, plutonium metal, plutonium oxide, and plutonium tetrafluoride. The heterogeneous nature of the SS\&C material and the slow oxidation of any calcium metal and plutonium metal make it difficult to provide an exact composition of any given item.

The heel from the attempt to dissolve SS\&C residue material was designated as IDC 393. The SS\&C heel material will be packaged for disposal at the Waste Isolation Pilot Plant. The material in IDC 387 was generated from the cleaning of the bomb reduction glovebox. The sweepings were collected and burned in a muffle furnace two times before they were removed from the glovebox.

Those two additional IDC categories are:

IDC 387 Reburned SS\&C Sweepings

IDC 393 Sand, Slag, and Crucible Heel. 
The SS\&C materials are at least nine years old; some materials may be 15 to 20 years old. The plutonium may be present as plutonium oxide, plutonium tetrafluoride, and/or plutonium metal. It is probable that the plutonium metal may only be present in the IDCs 390, 392, and 395 (unpulverized material). In those IDCs, the plutonium metal would be encapsulated in the calcium fluoride slag and thus protected from oxidation. The plutonium distribution varies within each IDC. It is not possible to present an exact plutonium distribution because many items are packaged in drums and there are no records for the individual items in some drums, not even how many items are in the drum, much less what the plutonium content of those individual items might be. The only information for those drums is the total net weight and the total plutonium weight. Table 1 reports the plutonium distribution for individually identified items in vaults or drums. The plutonium contents in the drums with umidentified items are less than 20 weight $\%$, with most of those drums having overall plutonium contents of less than 10 weight $\%$.

Prior to shipment to SRS, RFETS plans to pulverize the SS\&C material in an air-atmosphere glovebox. That pulverization is done so as to provide a more compact material for shipment to SRS and to facilitate oxidation of any reactive metals, i.e., calcium and plutonium. .

Table 1. Plutonium Distribution for Individually Identified SS\&C Items in Vaults or Drums

\begin{tabular}{|c|c|c|c|c|c|c|c|c|}
\hline IDC & 387 & 390 & 391 & 392 & 394 & 395 & 396 & 398 \\
\hline Total $\mathrm{Kg}$ in IDC & 3.6 & 20.8 & 758.0 & $1,614.1$ & 78.5 & 29.8 & 0.9 & 530.3 \\
\hline $\begin{array}{l}\text { Kg of Known } \\
\text { Individual Items in } \\
\text { IDC }\end{array}$ & 3.6 & 1.8 & 303.9 & 931.8 & 78.5 & 28.1 & 0.9 & 530.3 \\
\hline $\begin{array}{l}\text { Kg with of } \\
<l \text { wt\% } P u\end{array}$ & & 0.3 & 33.9 & 100.6 & 25.3 & 17.3 & & \\
\hline $\begin{array}{l}\mathrm{Kg} \text { with } \\
1-<10 \text { wt\% } \mathrm{Pu}\end{array}$ & & & 267.0 & 763.2 & 9.9 & 10.8 & 0.9 & 472.8 \\
\hline $\begin{array}{l}\mathrm{Kg} \text { with } \\
10 .<20 \text { wt\% } \mathrm{Pu}\end{array}$ & 0.6 & 1.5 & & 53.9 & 23.4 & & & 44.7 \\
\hline $\begin{array}{l}\mathrm{Kg} \text { with } \\
20-<30 \text { wt\% } \mathrm{Pu}\end{array}$ & & & 1.6 & 8.8 & 14.2 & & & 9.8 \\
\hline $\begin{array}{l}\mathrm{Kg} \text { with } \\
30 .<40 \text { wt \% } \mathrm{Pu}\end{array}$ & 1.0 & & 1.4 & 0.9 & & & & 3.1 \\
\hline $\begin{array}{l}\mathrm{Kg} \text { with } \\
40-<50 \text { wt } \% \mathrm{Pu}\end{array}$ & & & & 1.6 & & & & \\
\hline $\begin{array}{l}\mathrm{Kg} \text { with } \\
50-<60 \text { wt } \% \text { Pu }\end{array}$ & 2.0 & & & 1.4 & & & & \\
\hline $\begin{array}{l}\mathrm{Kg} \text { with } \\
60-<70 \text { wt\% Pu }\end{array}$ & & & & 1.5 & & & & \\
\hline
\end{tabular}

\subsection{Results from RFETS Solid Residue Characterization Program}

A major characterization program has been conducted over the past three years at RFETS. A statistical set of samples was obtained for each IDC and specific analyses were done. The results of the SS\&C characterization are given in Table 2. To assist with the interpretation of that table, the following information is provided that describes the bases for the tests and other terminology.

\subsubsection{Radiation Dose Readings}

The contact radiation dose was measured for the sampled items that were stored in drums or in walk-in vaults as part of the Solid Residue Characterization Program. If the contact dose rate was less that 200 $\mathrm{mREM} /$ hour the item was given a pass rating, otherwise the item was given a fail rating. No contact radiation dose rate measurements were obtained for the items that had been stored in the Building 371 Stacker/Retriever (S/R) vault (i.e., all items stored in stacker cans) because those items were never removed from the glovebox. 
WSRC-TR-98-00311

September 22, 1998

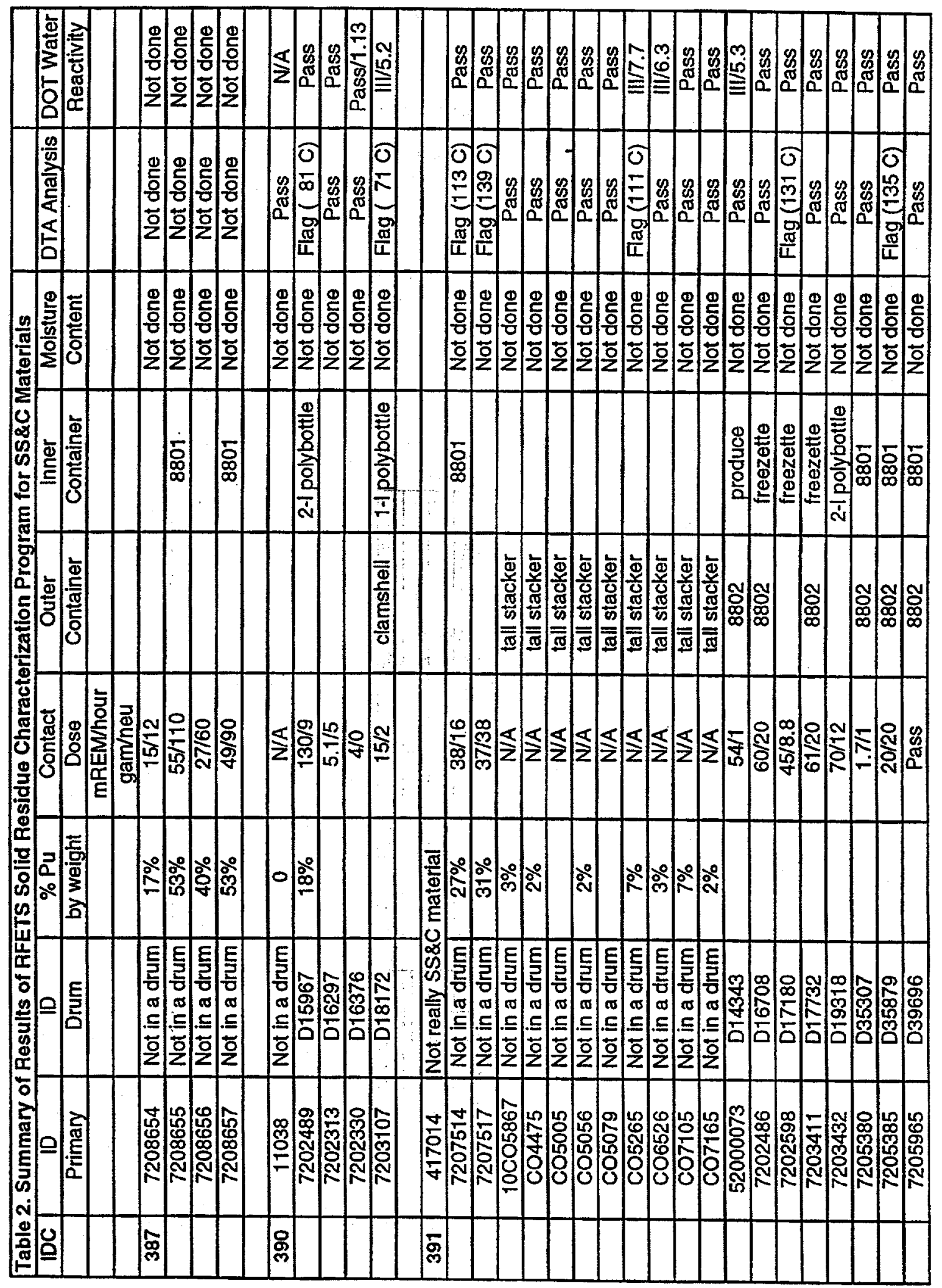




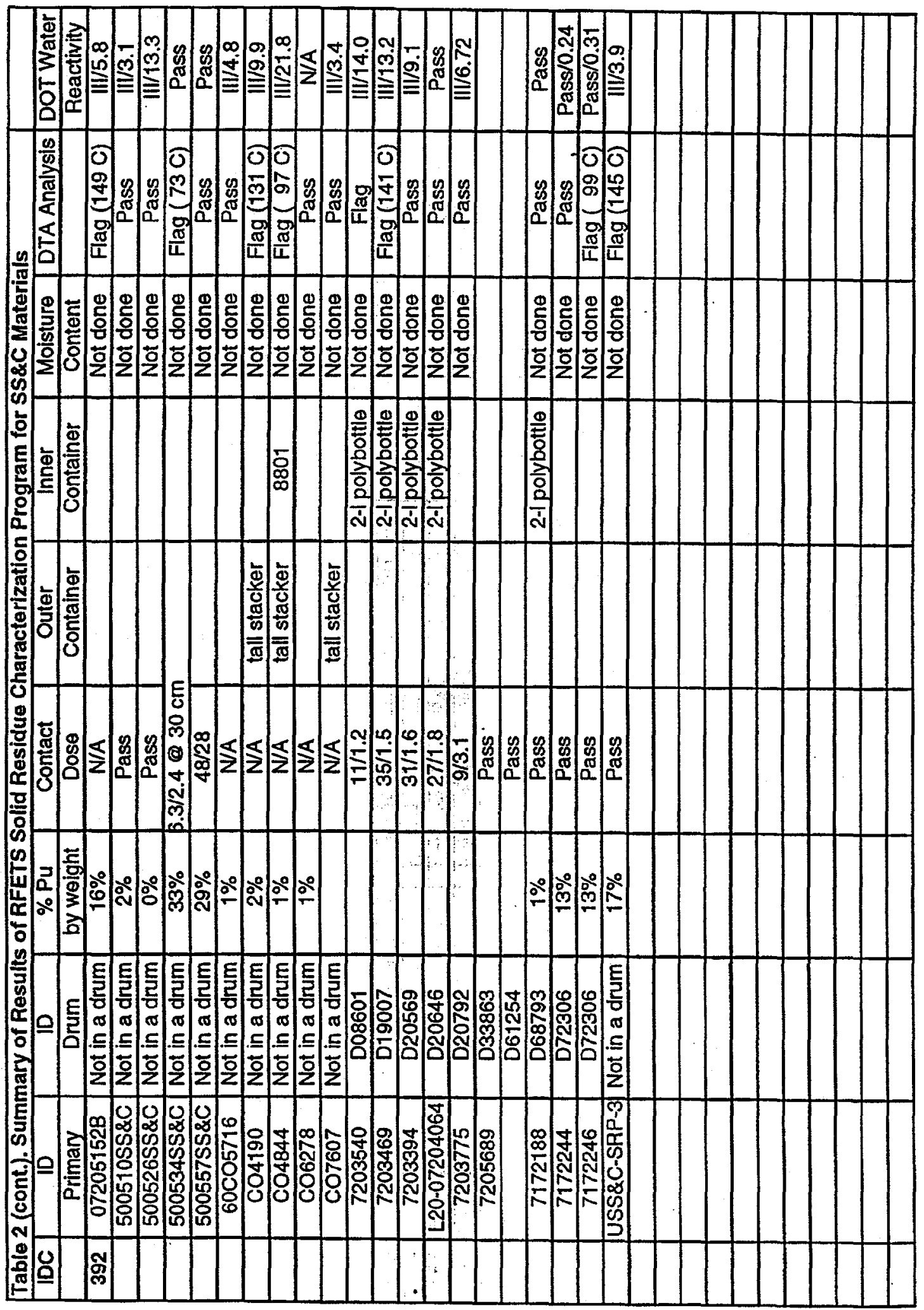




\begin{tabular}{|c|c|c|c|c|c|c|c|c|c|}
\hline IDC & ID & ID & $\% \mathrm{Pu}$ & Contact & Outer & Inner & Moisture & DTA Analysis & DOT Water \\
\hline & Primary & Drum & by weight & Dose & Container & Container & Content & & Reactivity \\
\hline \multirow[t]{11}{*}{394} & $\mathrm{CO4813}$ & Not in a drum & $1 \%$ & NA & tall stacker & & Not done & Pass & Pass \\
\hline & C05028 & Not in a drum & $6 \%$ & $\mathrm{~N} / \mathrm{A}$ & & & Not done & Pass & Pass \\
\hline & C05563 & Not in a drum & $1 \%$ & N/A & tall stacker & & Not done & Pass & Pass \\
\hline & C05813 & Not in a drum & $1 \%$ & N/A & & & Not done & Pass & Pass \\
\hline & 007177 & Not in a drum & $2 \%$ & N/A & & & Not done & Pass & Pass \\
\hline & 7241520 & D43450 & $1 \%$ & $2 / 4.4$ & & & & & \\
\hline & 7207927 & D49181 & $26 \%$ & $2.4 / 2.9$ & & & Not done & Flag $(133 \mathrm{C})$ & Pass/0.23 \\
\hline & 7170557 & D49869 & $14 \%$ & $31 / 7.6$ & & 8801 & Not done & Pass & Pass \\
\hline & 7172326 & D56582 & $15 \%$ & 4-Dec & & & Not done & Flag $(108 \mathrm{C})$ & Pass \\
\hline & 7172331 & D73416 & $21 \%$ & $27 / 28$ & & & Not done & Pass & Pass \\
\hline & & & & & & & & & \\
\hline \multirow[t]{6}{*}{395} & 004534 & Not in a drum & $2 \%$ & $\mathrm{~N} / \mathrm{A}$ & & 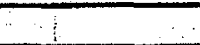 & Not done & Pass & III/6.4 \\
\hline & C05290 & Not in a drum & $2 \%$ & N/A & tall stacker & 1 & Not done & Flag $(143 C)$ & $111 / 8.2$ \\
\hline & $\operatorname{co5} 728$ & Not in a drum & $1 \%$ & $N / A$ & $i$ & - & Not done & Pass & Pass \\
\hline & C05744 & Not in a drum & $1 \%$ & $\mathrm{~N} / \mathrm{A}$ & 1 & & Not done & Pass & III/2.0. \\
\hline & C06699 & Not in a drum & $4 \%$ & $\mathrm{~N} / \mathrm{A}$ & tall stacker & & Not done & $F \operatorname{lag}(136 \mathrm{C})$ & $111 / 4.1$ \\
\hline & & & & & & & & & \\
\hline \multirow[t]{14}{*}{398} & C00397 & Not in a drum & $12 \%$ & $\mathrm{~N} / \mathrm{A}$ & & & Not done & Pass & Pass \\
\hline & C00569 & Not in a drum & $7 \%$ & N/A & & & Not done & Pass & Pass \\
\hline & C00664 & Not in a drum & $36 \%$ & N/A & short stacker & & Not done & Flag $(135 \mathrm{C})$ & III/4.3 \\
\hline & $\mathrm{c00764}$ & Not in a drum & $28 \%$ & N/A & short stacker & & Not done & Flag ( $91 \mathrm{C})$ & $111 / 2.9$ \\
\hline & $\mathrm{CO0947}$ & Not in a drum & $5 \%$ & N/A & & & Not done & Pass & $111 / 7.5$ \\
\hline & CO0999 & Not in a drum & $8 \%$ & $\mathrm{~N} / \mathrm{A}$ & short stacker & & Not done & Flag $(138 \mathrm{C})$ & Pass \\
\hline & $\mathrm{C01263}$ & Not in a drum & $24 \%$ & $\mathrm{~N} / \mathrm{A}$ & & & 0.35 & Flag $(82 C)$ & Pass \\
\hline & 7836155 & $\mathrm{D} 23422$ & $13 \%$ & $45 / 7$ & & & Not done & Flag (139 C) & III/12.4 \\
\hline & 7836087 & D23422 & $7 \%$ & $32 / 6$ & & & Not done & Pass & IIII11.0 \\
\hline & 7836029 & D56161 & $2 \%$ & $50 / 3$ & & 2-1 polybottle & Not done & Pass & III/12.0 \\
\hline & 7836173 & D59248 & $2 \%$ & $40 / 3$ & & & Not done & Pass & III/11.6 \\
\hline & 7836110 & D64111 & $13 \%$ & 7-Oct & & & Not done & Flag (142 C) & III/15.09 \\
\hline & 7836166 & D64557 & $6 \%$ & $107 / 5$ & & 2-1 polybottle & Not done & Flag $(96 \mathrm{C})$ & $111 / 11.6$ \\
\hline & 7836212 & D65227 & $6 \%$ & $106 / 7$ & & & Not done & Pass & Pass \\
\hline
\end{tabular}


Table 2 contains the contact radiation dose readings for most of the sampled SS\&C items that were stored in drums or walk-in vaults. As can be seen, none of the measured items had a contact radiation dose rates greater than $200 \mathrm{mREM} /$ hour (combined gamma and neutron radiation dose readings). Typically the gamma radiation dose measurements were higher than the neutron radiation dose readings.

Table 2 includes a description of the packaging of the sampled items. That information is presented to complement the radiation dose exposure data. Material was typically packaged directly into an inner container in the glovebox, then removed from the glovebox using a polvinylchloride bag, that package may have been placed a second bag (polyethylene), and the entire package placed in an outer container. The inner and outer containers could have been fabricated from plastic, stainless steel, or mild steel. There was little shielding against any neutron radiation dose. Similar neutron shielding is expected for the items that are packaged for placement in the 9975 Package for shipment to SRS. That packaging will involve placing the SS\&C material in a 1-liter, mild-steel produce can, removing that can from glovebox in a nylon bag, and placing that bagged item into a larger, mild-steel produce can.

\subsubsection{Drum or Walk-in Vault Storage}

Typically, if an item was stored in a drum or a walk-in vault, the material was packaged in an inner container, bagged out of the glovebox, and placed in an outer container. The containers are described below.

\subsection{Outer containers}

The 8802 can is a stainless-steel, slip-lid, 2 -liter container. The lid was taped to the container.

The clamshell is a plastic, 4-liter container. The clamshell consisted of two half shells that were screwed together and then taped.

\subsection{Inner Containers}

The 8801 can is a stainless-steel, slip-lid, l-liter container. The lid was taped to the container after it had been screwed into place.

The freezette is a 1-liter, plastic, screw-top container. The lid was taped to the container after it had been screwed into place.

The produce can is a 1-liter, mild-steel container. The container was sealed using a can sealer.

The polybottle is a one- or two-liter plastic bottle with a screw-top lid.

\subsubsection{Building 371 Stacker/Retriever Storage}

The Building $371 \mathrm{~S} / \mathrm{R}$ Vault is a contaminated storage facility in which items are handled via remote operations. If the item was stored in the Building $371 \mathrm{~S} / \mathrm{R}$ vault, then the outer container was either a tall stacker can or a short stacker can. Often the material was placed directly into the stacker cans without an inner can. The tall-stacker can has a volume of 2.7 liters and the short-stacker can has a volume of 1 liter. The stacker cans are stainless steel.

\subsubsection{Moisture Content}

The weight loss at $100^{\circ} \mathrm{C}$ was measured for select items. That weight loss was attributed entirely to water. The table contains the percent of the material that was lost at the clevated temperature.

\subsubsection{DrA Analysis}

The SS\&C samples were subjected to a Differential Thermal Analysis (DTA) test to determine the behavior of the material up to $150^{\circ} \mathrm{C}$. In part, the DTA analyses were dictated by storage criteria set forth in the RFETS Health and Safety Practices (HSP) Manual, Section 31.11. The RFETS HSP manual dictates special storage conditions for materials with greater than 30 weight\% plutonium if there is the potential for the stored material to undergo exothermic reactions at temperatures up to $150^{\circ} \mathrm{C}$. If an exotherm was present on the DTA scan with an onset temperature of less than $150^{\circ} \mathrm{C}$, that result was flagged for further 
examination. That examination included an evaluation of the enthalpy change. The entahlpy change was restricted to 10 joules/gram of plutonium. A sample would fail the analysis if a DTA exotherm met both the onset temperature criterion and the enthalpy change criterion. None of the SS\&C samples failed this analysis. The temperatures given in the DTA Analysis column of Table 2 refer to the onset temperatures of exotherms at less than $150^{\circ} \mathrm{C}$, as determined by the RFETS Solid Residue Characterization Program.

\subsubsection{DOT Water Reactivity}

The DOT water reactivity test was based on the test method described in the Code of Federal Regulations (CFR) 10.173 Appendix E for Division 4.3 Dangerous When Wet Materials. The SS\&C materials either passed the test (i.e., evolution of gas was less than one liter/kilogram material/hour) or reacted slowly with water at ambient temperatures to generate gas at a rate of one to less than 20 liters/ kilogram material/hour (Packing Group III). If a number is given for the DOT Water Reactivity, it is the total gas generation /kilogram material over the entire seven hours that was measured for a particular sample.

\subsection{Potential Reactions}

There are several types of chemical reactions that are of concern in developing the safety envelope for a shipping container. Among those reactions are hydrogen gas generation from the reaction of ambient or absorbed water with reactive metals, and pyrophoric reactions within the bounding temperature of the package. Those reactions that are germane to the shipping of the SS\&C residues in the 9975 package are discussed in the following sections.

\subsubsection{Reactions with Water}

The water reactivity results from the RFETS Solid Residue Characterization Program demonstrate that the RFETS SS\&C materials, even the materials that have been pulverized for close to 10 years or longer, do have the potential to generate gas when exposed to water. It is reasonable to assume that some reactive metal could be encapsulated in the slag and only exposed during the sampling and water reactivity test. Furthermore, if that material had been stored in the Building 371 S/R vault, then the vault's nitrogen atmosphere would have inhibited the oxidation of any metals. Both calcium metal and plutonium metal are potential sources of water reactivity in the SS\&C material. Only water vapor reactions are considered because regulations proscribe the presence of free liquid (i.e., bulk water) in the shipping containers. Furthermore, because the 9975 Package is a double-containment vessel, the ingress of water during an accident scenario is not considered credible.

\subsubsection{Calcium/Water Vapor Reaction}

One bounding estimate for the amount of calcium in the SS\&C material can be made using the amount of gas generated in the worst result for the water reactivity tests conducted for the RFETS Solid Residue Characterization Program. The worst gas generation was from a sample of IDC 392 material; a total of 21.8 Jiters/kilogram of material of gas was generated during the seven-hour test time. Using nominal values for temperature (room temperature $21^{\circ} \mathrm{C}$ ) and pressure $\left(615\right.$ torr for 6600 -foot elevation of RFETS), ${ }^{\prime}$ the calculated number of moles of hydrogen gas in the 21.8 liters is 0.73 . The calcium reaction with water proceeds by the reaction:

$$
\mathrm{Ca}+2 \mathrm{H}_{2} \mathrm{O} \rightarrow \mathrm{Ca}(\mathrm{OH})_{2}+\mathrm{H}_{2} \text {. }
$$

As the number of moles of hydrogen generated equals the number of moles of calcium, there were 0.73 moles of calcium/kilogram of material, or 29.3 grams/kilogram of material, in the previously-mentioned sample. The calcium concentration in the slag material would then be 2.93 weight\%.

\footnotetext{
${ }^{1}$ Karen A. Phillips, Solid Residue Characterization Program, Safe Sites of Colorado, private communication. July 21, 1998. Those values were used by the SSOC personnel to calculate the number of moles of hydrogen generated from the water reactivity test data. Those values are typical of the values expected and may be in error by about $2 \%$.
} 
Another source for an estimate of the calcium content in the RFETS unpulverized slag is from tests that were done at the Savannah River Technology Center. ${ }^{2}$ According to those tests, RFETS slag chunks have a calcium composition of $0-5$ weight $\%$. The 5 weight\% value for the calcium concentration represents a worse case for reactivity than the RFETS 2.9 weight\% value. The 5 weight\% value will be used in subsequent discussions.

The safety analysis of the 9975 Package is expected to allow 19 grams of water to be present in the package as adsorbed onto the surfaces of the materials and present in the gas phase. The 19 grams of water are equivalent to 1.1 moles of water. The density of pulverized SS\&C material is reported as 2.1 grams/milliliter. ${ }^{3}$ If a one-liter inner container is used, then about 2.1 kilograms of pulverized material could be packaged in that container. Using a calcium content of 5 weight\%, there would be 105 grams of calcium in that container and a total of 210 grams of calcium in the two containers that are placed in the 9975 Package. The 210 grams of calcium correspond to 5.2 moles of calcium. The 1.1 moles of water could react with 0.55 moles of calcium to produce 0.55 moles of calcium hydroxide and 0.55 moles of hydrogen gas. The remaining 4.6 moles of calcium would be available for other reactions, most likely the oxidation of calcium to calcium oxide. It is unlikely that any of the remaining elemental calcium would combine with hydrogen to form calcium hydride at the operating temperature of the 9975 Package. That reaction requires higher temperatures, i.e., and $150-250^{\circ} \mathrm{C} .^{4}$

The heat of reaction for the reaction between calcium and water vapor to form calcium hydroxide and hydrogen gas was calculated at ambient temperature. It is expected that the water will be present in the vapor phase for reactions, i.e., no bulk water will be present. The details of those calculations for one mole of calcium are given in Appendix A. The thermodynamic values were obtained from the JANAF Thermochemical Tables. ${ }^{5}$ The heat of reaction for the reaction of 1.1 moles of water with 0.55 moles of calcium is 275 kjoules at $25^{\circ} \mathrm{C}$.

The bulk calcium probably will be present in pieces or beads. The pulverization and sieving processes are designed to produce an SS\&C material that has particles no larger than one-quarter inch diameter. For this analysis, it is assumed that the calcium is present as beads with an average diameter of one-eighth inch. Using 1.55. grams/milliliter as the density of calcium, the 105 grams of calcium in one container would be present in about 4,040 one-eighth diameter beads ( 8,080 one-eighth diameter beads in two containers). Calculations for the beads are given in Appendix $B$.

Nissen studied the oxidation rate of calcium in an argon atmosphere saturated with water. ${ }^{6}$ According to Nissen, there was an initial rapid increase in the weight gain of the calcium samples. That initial phase lasted only for a few hours and was followed by a linear increase in the weight gain of the calcium samples with time. After some period of time (less than 100 hours), the weight gain of the calcium samples began to decrease with time. From $25^{\circ} \mathrm{C}$ to $150^{\circ} \mathrm{C}$, the linear oxidation rate decreased with the higher temperatures.

Consider only the linear oxidation at 22 tort of water vapor. At $25^{\circ} \mathrm{C}$ the linear oxidation rate given by Nissen is 1.00 milligram $/ \mathrm{cm}^{2}$ hour. If 22 grams ( 0.55 moles) of calcium react with the 19 grams of water vapor, then 0.00272 grams of calcium will react per bead. The calculated reaction time for the water vapor with the calcium is about nine hours. Appendix $\mathrm{C}$ describes the model used to determine the time for a

\footnotetext{
${ }^{2}$ D. G. Karraker, J. H. Gray, T.S. Rudisill, R. R. Livingston, F. R. Graham, E. A. Kyser, III, A. M. Murray, R. A. Pierce, J. I. Mickalonis, and D. B. Allen; Flowsheet Modifications for Dissolution of Sand, Slag, and Crucible Residues in F-Canyon Dissolvers; WSRC-TR-97-00395, December 1997.

${ }^{3}$ E. Conrad, "Re[2] Bounding Values for SS\&C and PuF 4 Isotopics", e-mail, July 15, 1998.

4Comprehensive Inorganic Chemistry. Volume I; J. C. Bailar, Ir., ed.; Pergamon Press; Oxford; 1973.

${ }^{5}$ M. W. Chase, Jr., C. A. Davies, J. R. Sowney, Jr., D. J. Frurip, R. A. McDonald, and A. N. Syverud; JANAF Thermochemical Tables, Third Edition; American Chemical Society/American Institute of Physics for National Bureau of Standards; New York; 1986.

${ }^{6}$ D. A. Nissen. The Low-Temperature Oxidation of Calcium by Water Vapor, Oxidation of Metals, $11(5)$, $241(1977)$.
} 
WSRC-TR-98-00311

September 22, 1998

reaction. The average rate of heat generation from that nine-hour reaction is about 8 watts. If the reaction does proceed at that rate, then both the initial rapid weight gain and the linear weight gains would be completed before the two containers are placed into the 9975 Package. Any heat generated by the ninehour reaction will be dissipated into the storage area of the containers.

It is reasonable to expect a longer reaction time because the water.vapor pressure over the adsorbed water is less than the equilibrium pressure of water vapor over condensed water. Both calcium fluoride ${ }^{789}$ and magnesium oxide ${ }^{11} 12^{1314}$ adsorb water as physisorbed water and as chemisorbed water. Nissen measured the oxidation rate in an argon atmosphere with 5.5 torr water vapor. That oxidation rate was 0.055 milligrams $/ \mathrm{cm}^{2}$ hour. The reaction time was calculated as 169 hours (about 7 days) based on the model in Appendix $C$. Heat generation rate from that reaction would be 0.45 watts.

Calculations show that if the calcium/water vapor reaction takes longer than eight days, then the heat generation rate would be less than 0.39 watts. It is expected that there will be a lag between the time that the SS\&C material is placed in a container and the time that the container is placed into the 9975 Package. A time lag of two weeks is not unreasonable. Therefore, the heat from any rapid reaction would be dissipated into the containers' storage environment. If the reaction takes longer than eight days, then the associated wattage from the reaction should not be a problem for the 9975 Package.

\subsubsection{Calcium Oxide/Water Vapor Reaction}

There are competing reactions for the water. $1516: 1718$ Calcium oxide is a by-product of the oxidation of calcium metal and is expected to be present in the SS\&C material. In moist air, calcium oxide readily forms calcium hydroxide $\left(\mathrm{Ca}\left[\mathrm{OH}_{2}\right)\right.$ and calcium carbonate $\left(\mathrm{Ca}_{2}\left[\mathrm{CO}_{3}\right]\right)$ per the reaction:

$$
2 \mathrm{CaO}+\mathrm{H}_{2} \mathrm{O}_{\text {vapor }}+\mathrm{CO}_{2} \rightarrow \mathrm{Ca}(\mathrm{OH})_{2}+\mathrm{CaCO}_{3} \text {. }
$$

The amount of $\mathrm{CaO}$ present in the SS\&C material is not well defined. For the purposes of this analysis, it is assumed that there is sufficient $\mathrm{CaO}$ present to react with all of the water vapor. The 1.1 moles of $\mathrm{H}_{2} \mathrm{O}$ would require 2.2 moles of $\mathrm{CaO}$. The limiting reagent for the reaction then becomes the carbon dioxide $\left(\mathrm{CO}_{2}\right)$. Using nominal values for temperature and pressure at RFETS $\left(21^{\circ} \mathrm{C}\right.$ and 615 torr) and for the

${ }^{7}$ G. B. Amphlett, "The Adsorption of Water Vapour by Calcium Fluoride", Transactions of the Faraday Society, 54, 1206(1958).

${ }^{8}$ Peter B. Barraclough and Peter G. Hall; "Adsorption of Water Vapour by Calcium Fluoride, Barium Fluoride, and Lead Fluoride"; Journal of the Chemical Society, Faraday Transactions I; 11; 2266(1975).

Y Yasushige Kuroda;"Effect of Chemisorbed Water on the Two-dimensional Condensation of Water and Argon on $\mathrm{CaF}_{2}$ "; Journal of the Chemical Society, Faraday Transactions $1 ; 181 ; 757$ (1985).

${ }^{10}$ Yasushige Kuroda, Tohru Takenaka, Junzo Umemura, Shigeharu Kittaka, Kunimitsu Morishige, and Tetsuo Morimoto: "Adsorption of $\mathrm{H}_{2} \mathrm{O}$ and Ar on Pulverized $\mathrm{CaF}_{2}$ "; Langmuir; $1 ; 679$ (1985).

"Salvatore Coluccia, Alan Barton, and Anthony J. Tench; "Reactivity of Low-coordination Sites on the Surface of Magnesium Oxide"; Journal of the Chemical Society, Faraday Transactions I; 77, 2203(1981).

${ }^{12}$ T. H. Nielsen and M. H. Leipold, "Surface Hydroxyl in MgO", Journal of the American Ceramic Society, $49(11), 626(1966)$.

${ }^{13}$ I. O. Wilson, "Magnesium oxide as a high-temperature insulant", IEEE Proceedings Part A, 128(3), 159(1981).

14 Nora H. de Leeuw, Graeme W. Watson, and Stephen C. Parker; "Atomistic simulation of adsorption of water on three-, flour-, and five-coordinated surface sites of magnesium oxide"; Journal of the Chemical 'Society, Faraday Transactions; $92(12), 2018$ (1996).

${ }^{15}$ Kingzetts Chemical Encyclopedia; D. H. Hey, ed.; D. Van Nostrand Company, Inc.; New Jersey, 1966.

${ }^{16}$ International Encyclopedia of Chemical Science, D. Van Nostrand Company, Inc.; New Jersey, 1964.

${ }^{17}$ Hawley's Condensed Chemical Dictionary, Eleventh Edition; N. Irving Sax and Richard J. Lewis, Sr., eds.: Van Nostrand Reinhold Company; New York; 1987.

${ }^{18} \mathrm{~J}$. W. Mellor; A Comprehensive Treatise on Inorganic and Theoretical Chemistry, Volume IIr; Longmans, Green and Company; London: 1946. 
concentration of $\mathrm{CO}_{2}$ in air ( 0.033 volume\%), the number of moles of $\mathrm{CO}_{2}$ available in the 0.12069 cubic feet of void space in the 9975 Package is $3.8 \times 10^{.5}$. Therefore, only $7.6 \times 10^{-5}$ moles of CaO could react to form the $\mathrm{Ca}(\mathrm{OH})_{2}$ and $\mathrm{CaCO}_{3}$.

The heat of reaction for the reaction among calcium oxide, water vapor, and carbon dioxide to form calcium hydroxide and calcium carbonate was calculated at ambient temperature. The details of the calculation for one mole of calcium oxide are given in Appendix D. The thermodynamic values were obtained from the JANAF Thermochemical Tables and Thermochemical Properties of Inorganic Substances. ${ }^{19}$ The heat of reaction for the reaction of $3.8 \times 10^{-5}$ moles of water with $7.6 \times 10^{-5}$ moles of calcium oxide would be about $1.1 \times 10^{-2}$ kjoules at $25^{\circ} \mathrm{C}$. The réaction would generate heat at a rate less than 0.005 watts if it occurred in one hour or less than 0.20 watts if it occurred in one minute. That reaction should not be a problem for the 9975 Package.

\subsubsection{Plutonium/Water Vapor Reactions}

It is expected that some of the plutonium in SS\&C material will be present as the metal. The behavior of plutonium metal in a moist atmosphere has been the subject of several recent studies. ${ }^{20} 21$ The intense interest in this topic is motivated by the need to establish procedures for the safe handling and storage of plutonium metal. Without an understanding of the environmental effects on plutonium, procedures may be inadequate or inappropriate.

Kinetic studies ${ }^{21}$ showed that reaction of plutonium metal in moist air exhibited several different behaviors based on temperature. At temperatures below $75^{\circ} \mathrm{C}$, the reaction product is plutonium oxide whereas at higher temperatures $\left(75^{\circ} \mathrm{C}-135^{\circ} \mathrm{C}\right)$ the product is plutonium monoxide monohydride. There does not seem to be any significant difference in the activation energy for these two products. The activation energies vary with water pressure from $17.9 \mathrm{kcal} /$ mole in dry air (less than $1 \mathrm{ppm}$ water vapor) to 34.4 $\mathrm{kcal} / \mathrm{mole}$ in water-saturated air.

Those kinetic studies also indicated that the behavior of plutonium in a moist atmosphere is characterized by two regimes: a moisture-independent regime and a moisture-dependent regime. Only the moisturedependent regime is discussed in this section. The moisture-dependent regime is bounded between $-25^{\circ} \mathrm{C}$ and $200^{\circ} \mathrm{C}$ with a maximum rate of reaction at about $110^{\circ} \mathrm{C}$. The minimum water vapor concentration for this regime is $0.5 \mathrm{ppm}$. No dependence on oxygen concentration was observed for this regime. The reaction rate $(R)$ as function of water pressure at $25^{\circ} \mathrm{C}$ is given by:

The units of $R$ are $\mathrm{mg} / \mathrm{cm}^{2}$ min and $P_{\mathrm{H} 2 \mathrm{O}}$ is in torr.

$$
\ln \mathrm{R}=-12.60+0.498 \ln \mathrm{P}_{\mathrm{H} 2 \mathrm{O}}
$$

The rate of the plutonium/water vapor reaction can be used to gauge whether the heat from the reaction will be a problem for the 9975 Package. At room temperature $\left(25^{\circ} \mathrm{C}\right)$, it is assumed that the partial pressures of water and oxygen in the 9975 Package are 22 torr and 160 torr, respectively. For those conditions, Raynor and Sackman report a measured rate of $1.01 \times 10^{-5} \mathrm{mg} / \mathrm{cm}^{2} \mathrm{~min}$. ${ }^{22}$ Processing requirements for F-Canyon dissolution limit the amount of plutonium in a container to 330 grams. There are two containers placed in each 9975 Package. For this estimate, it is assumed that all the plutonium is present as metal beads (See Appendix B). The metal beads are assumed to have an average diameter of one-eighth inch $(0.318 \mathrm{~cm})$. Using $19.84 \mathrm{grams} / \mathrm{milliliter}$ as the density of alpha-phase metal, the 330 grams of plutonium in each container will be dispersed into 991 beads. Each bead will have a surface area of $0.320 \mathrm{~cm}^{2}$. Based on

\footnotetext{
${ }^{19}$ I. Barin and O. Knacke, Thermochemical Properties of Inorganic Substances, Springer-Verlag, Berlin, 1973.

20 John Haschke, Reactions of Plutonium and Uranium with Water: Kinetics and Potential Hazards, Los Alamos National Laboratory Report LA-13069, December 1995:

${ }^{21}$ John M. Haschke. Thomas H. Allen, and Jerry L. Stakebake; Reaction Kinetics of Plutonium with Oxygen, Water, and Humid Air: Moisture Enhancement of the Corrosion Rate", Journal of Alloys and Compounds, 243, 23(1996).

${ }^{22}$ J. B. Raynor and J. F. Sackman, Nature, 197, 588(1963).
} 
these assumptions, the model in Appendix C, and using the Raynor and Sackman rate, the amount of plutonium that reacts over two years per bead is 0.00341 grams or about 13 grams $(0.055$ moles $)$ of plutonium out of the 660 grams of plutonium in the 9975 Package.

An estimate of the heat generated from this reaction can be made by assuming that the reaction is:

$$
\mathrm{Pu}+2 \mathrm{H}_{2} \mathrm{O}_{\text {vipor }} \rightarrow \mathrm{PuO}_{2}+2 \mathrm{H}_{2} \text {. }
$$

Using thermodynamic data from the JANAF Thermochemical Tables and from the Bureau of Mines Bulletin $672^{23}$, the heat of the reaction for the 13 grams of plutonium (0.055 moles of plutonium) is estimated as about 32 kjoules at $25^{\circ} \mathrm{C}$. Details of the calculations for one mole of plutonium are given in Appendix $\mathrm{E}$. That heat would be generated gradually over the two years at an average rate of $5 \times 10^{-4}$ watts.

There were two unanticipated results in the study by Haschke, Allen, and Stakebake that led to their proposed mechanism of the plutonium/water vapor reaction. First, there was no indication that the water was being depleted. Second, no hydrogen gas was detected as a by-product of the reaction of plutonium with water vapor. Haschke, Allen, and Stakebake concluded that the reaction of plutonium with water vapor is a multistep reaction in which the catalytic properties of plutonium oxide dictate how the overall reaction proceeds. They proposed the following reaction mechanism. It is assumed that a layer of plutonium oxide covers the plutonium metal. The water vapor is adsorbed onto the surface of the plutonium oxide.

$$
\mathrm{H}_{2} \mathrm{O}_{\text {vapor }} \rightarrow \mathrm{H}_{2} \mathrm{O}_{\text {adsorbed }}
$$

The adsorbed water then reacts with the plutonium metal to form plutonium oxide and hydrogen atoms that are adsorbed onto the plutonium oxide surface.

$$
2 \mathrm{H}_{2} \mathrm{O}_{\text {adsorbed }}+\mathrm{Pu}_{\text {solid }} \rightarrow \mathrm{PuO}_{2 \text { eolid }}+4 \mathrm{H}_{\text {adsorted }}
$$

At the same time oxygen may be absorbed by the plutonium oxide surface to produce oxygen atoms.

$$
\mathrm{O}_{2} \text { gas } \rightarrow \mathrm{O}_{2} \text { adsorbed } \rightarrow 2 \mathrm{O}_{\text {adsorted }}
$$

The atomic hydrogen and oxygen can then react to form water on the catalytic plutonium oxide surface.

$$
2 \mathrm{H}_{2 \text { dsorted }}+\mathrm{O}_{\text {2dsorbed }} \rightarrow \mathrm{H}_{2} \mathrm{O}_{\text {adsorbed }}
$$

Based on that reaction scheme, as long as oxygen persists in a closed system, such as the 9975 Package, both the water concentration and the rate of plutonium reaction with the water remain constant. Hydrogen gas only forms in significant amounts after the oxygen has been depleted. The rate of the plutonium/water vapor reaction is sufficiently slow at room temperature, that the oxygen will not be depleted during two years. The amount of oxygen in the 9975 Package was estimated as 0.0240 moles using nominal values for the temperature and pressure at RFETS ( $21^{\circ} \mathrm{C}$ and 615 torr), the content of oxygen in air (20.9 volume\%), and the air space in the 9975 package $(0.12069$ cubic feet $)$.

\subsubsection{Pyrophoric Reactions}

There is no standard definition for pyrophoricity. A simple definition is any material that can ignite spontaneously in contact with air. No spontaneous ignitions were observed during the sampling of the SS\&C material. ${ }^{24}$

There is a DOT test for pyrophoricity. ${ }^{25}$ In the DOT test for pyrophoricity, the material is dropped from a height of about one meter onto a noncombustible surface. If no ignition is observed during dropping or within five minutes of impacting the surface, the material is not considered pyrophoric. None of the SS\&C material was tested per the DOT test for pyrophoricity. However, as part of the preparation to ship the SS\&C material to SRS, that material will be pulverized and sieved in an air-atmosphere glovebox. Such

\footnotetext{
${ }^{23}$ L. B. Pankratz, Thermodynamic Properties of Elements and Oxides, Bureau of Mines, United States Department of the Interior Bulletin 672, Government Printing Office, Washington D. C., 1982.

${ }^{24}$ Karen A. Phillips, Solid Residue Characterization Program, Safe Sites of Colorado, private communication, August 3, 1998.

25 49 CFR 173.124 and 49 CFR 173, Appendix E (CFR: Code of Federal Regulations).
} 
treatment should be sufficient to initiate any pyrophoric reactions that the DOT test would identify. Therefore, it is expected that any DOT pyrophoric species in the SS\&C material will have been stabilized, i.e., oxidized, prior to packaging the material for shipment.

\subsubsection{Calcium /Oxygen Reactions}

Elemental calcium reacts with oxygen to form calcium oxide. The oxidation of finely-divided calcium is spontaneous in air. As a result, finely-divided calcium is considered pyrophoric. ${ }^{26} 2728$ Any finely-divided calcium that is exposed in SS\&C material during the pulverization and sieving operations is expected to oxidize immediately. Only bulk calcium should be present in the SS\&C material that is packaged for shipment to SRS.

The bulk calcium probably will be present in pieces or beads. Although those beads of calcium are not expected to be pyrophoric, there will be a reaction with oxygen over time to generate calcium oxide. The rate of that reaction needs to be estimated to determine if the heat generated from the reaction has an impact on the SARP analysis. The pulverization and sieving processes are designed to produce an SS\&C material that has particles no larger than one-quarter inch diameter. For this analysis, it is assumed that the calcium is present as beads with an average diameter of one-eighth inch. Using 1.55 grams/milliliter as the density of calcium, the 105 grams of calcium in one of container would be present in about 4,040 one-eighth inch diameter beads.

A calcium oxide film forms on calcium metal in a dry oxygen atmosphere. ${ }^{29}$ According to Nissen, ${ }^{6}$ that film is about 0.1 microns thick. Using the model of 4.040 one-eighth inch diameter beads to describe the calcium metal, a total of about 0.0188 grams of calcium in one container would have reacted to form that oxide layer. For both containers, 0.0376 grams of calcium would have reacted to form the oxide layer.

Elemental calcium reacts with oxygen as follows:

$$
2 \mathrm{Ca}+\mathrm{O}_{2} \rightarrow 2 \mathrm{CaO} \text {. }
$$

The 0.0376 grams of calcium ( 0.000939 moles of calcium) that reacted to form the oxide layer would generate 0.0526 grams of calcium oxide $(0.000939$ moles). The heat of reaction of the 0.0376 grams of calcium can be estimated using data from the JANAF Thermochemical Tables. The results of those calculations for one mole of calcium oxide are given in Appendix F. The heat for the reaction of 0.000939 moles of calcium with 0.000470 moles of oxygen would be about 0.60 kjoules at $25^{\circ} \mathrm{C}$.

Once the calcium oxide layer forms, the continued oxidation of calcium proceeds at a rate of 0.003 milligrams $/ \mathrm{cm}^{2}$ hour. ${ }^{6}$ That rate applies to temperatures below $300^{\circ} \mathrm{C}$ and for calcium in a dry oxygen atmosphere. ${ }^{30}$ The total potential oxygen that is available for reaction includes the oxygen from air space in the 9975 Package and the oxygen from the radiolysis of the 1.1 moles of water vapor. Using nominal values for temperature and pressure at RFETS $\left(21^{\circ} \mathrm{C}\right.$ and 615 torr) and for the concentration of oxygen in air (20.9 volume\%), the number of moles of oxygen available in the 0.12069 cubic feet of void space in the 9975 Package is 0.0240 . The complete radiolysis of the 1.1 moles of water vapor would produce 0.55 moles of oxygen. A total of 0.574 moles of oxygen would be available to oxidize the calcium.

Using the model in Appendix C, about 260 days would be needed for 1.15 moles of calcium to react with all of the potentially available oxygen. The heat of reaction of the 1.15 moles of calcium can be estimated using data from the JANAF Thermochemical Tables. The results of those calculations for one mole of

\footnotetext{
${ }^{26}$ Fire Protection Guide to Hazardous Materials, Eleventh Edition; National Fire Protection Association, Massachusetts, 1994.

${ }^{27}$ L. Bretherick, Bretherick's Handbook of Reactive Chemical Hazards, Butterworths, London, 1990.

${ }^{28}$ The Merck Index, Eleventh Edition; Susan Budavari,ed.; Merck and Company, Incorporated; New Jersey: 1989.

29 The reaction of calcium with water vapor is discussed in Section 2.3.2.1.

30 The oxidation in the presence of water vapor is discussed in Section 2.3.1.1.
} 
calcium oxide are given in Appendix F. The heat of reaction for the reaction of 1.15 moles of calcium with 0.574 moles of oxygen would be about 729 kjoules at $25^{\circ} \mathrm{C}$. The average heat generation rate would be about 0.033 watts.

The main contribution to the oxygen is from the radiolysis of water. The radiolysis rate is estimated as $0.8 \times 10^{-3}$ moles/day. ${ }^{31}$ At that rate there would be insufficient oxygen available to support the calcium/oxygen reaction at the $0.003 \mathrm{milligrams} / \mathrm{cm}^{2}$ hour rate. Therefore, the radiolysis of water can be considered the rate-limiting step, and the calcium/oxidation rate would proceed more slowly. The average heat generation would be less than 0.33 watts.

\subsubsection{Plutonium/Oxygen Reactions}

It is expected that any pyrophoric plutonium, i.e., finely-divided plutonium, will react with oxygen in the air-atmosphere glovebox at RFETS as the SS\&C material is pulverized, sieved, and prepared for packaging. If it is assumed that all the remaining plutonium is present as one-eighth inch diameter metal beads, the specific surface area for the beads is approximately $0.5 \mathrm{~cm}^{2} / g r a m$. According to a compilation of plutonium studies by Stakebake ${ }^{32}$, plutonium with specific areas less than $10 \mathrm{~cm}^{2} / g r a m$ have ignition temperatures exceeding $450^{\circ} \mathrm{C}$. Therefore, the one-eight inch diameter beads should not ignite at the temperatures expected for the 9975 Package because the surface area/gram for those plutonium beads. is about $0.952 \mathrm{~cm}^{2} / \mathrm{gram}$.

The plutonium metal will react slowly with oxygen in the 9975 Package environment. The plutonium' oxygen reaction rate has been shown to be slower than that for the plutonium/water vapor reaction. ${ }^{21}$ At $25^{\circ} \mathrm{C}$ with a partial pressure of oxygen at 120 torr in a dry air atmosphere, Haschke, Allen, and Stakebake derive a reaction rate of $2.94 \times 10^{-6}$ milligrams $/ \mathrm{cm}^{2}$ minute. Processing requirements for F-Canyon dissolution limit the amount of plutonium in a container to 330 grams. There are two containers packaged in cach 9975 Package. For this estimate, it is assumed that all the plutonium is present as metal beads. The metal beads are assumed to have an average diameter of one-eighth inch $(0.318 \mathrm{~cm})$. Using 19.84 grams/milliliter as the density of alpha-phase metal, the 330 grams of plutonium in each can be dispersed into 991 beads. Each bead will have a surface area of $0.320 \mathrm{~cm}^{2}$. Based on these assumptions and using the Haschke, Allen, and Stakebake rate, the amount of plutonium that reacts over two years per bead is essentially negligible at 0.000989 grams per bead or about two grams of plutonium out of the 660 grams of plutonium in the 9975 Package (See Appendix C).

An estimate of the heat generated from this reaction can be made by assuming that the reaction is:

$$
\mathrm{Pu}+\mathrm{O}_{2} \rightarrow \mathrm{PuO}_{2}
$$

Using thermodynamic data from the JANAF Thermochemical Tables and from the Bureau of Mines Bulletin 672 , the heat of the reaction for the two grams of plutonium $(-0.008$ moles of plutonium) is estimated as about 8 kjoules at $25^{\circ} \mathrm{C}$. Details of the calculations for one mole of plutonium are given in Appendix $\mathrm{G}$. That heat will be generated gradually over the two years at an average rate less than 0.001 watts.

\subsubsection{Plutonium/Hydrogen Gas Reactions}

Plutonium metal readily reacts with hydrogen gas to form a solid-solution hydride. ${ }^{33}$ The plutonium hydride has a stoichiometry range of $\mathrm{PuH}_{\mathrm{x}}$ such that $2<\mathrm{x}<3$. The reaction between plutonium and hydrogen gas is presented in Katz, Seaborg, and Morss. ${ }^{34}$ Initially, $\mathrm{PuH}_{2}$ forms with the hydrogen atoms occupying the tetrahedral interstices between plutonium atoms. Excess hydrogen atoms continue to be incorporated

${ }^{31}$ Neal Askew, private communication, September 3, 1998.

32 J. L. Stakebake, Plutonium Pyrophoricity, Rocky Flats Plant Report RFP-4517, 1992.

${ }^{33} \mathrm{~J}$. M. Haschke, T. H. Allen, and J. C. Martz; Oxidation Kinetics of Plutonium in Air: Consequences for Environmental Dispersion; Los Alamos National Laboratory Report LA-UR-97-2592; July 1997.

${ }^{34}$ J. J. Katz, G. T. Seaborg, and L. R. Morss; The Chemistry of the Actinide Elements, Second Edition, Volume 1; Chapman and Hall, New York, 1986. 
into the lattice; the excess hydrogen atoms occupy the octahedral interstices of the lattice until the hydrogen: plutonium ratio is 2.75 . At that ratio, the hexagonal $\mathrm{PuH}_{3}$. begins to form. Once the hydrogen:plutonium ratio is between 2.9 and 3.0, only the hexagonal $\mathrm{PuH}_{3}$ exists.

It is expected that there will be hydrogen gas present in the 9975 Package from water radiolysis and/or from water reactions with calcium and plutonium. Therefore, it is anticipated that plutonium hydride will be present. If one assumes that the 19 grams of water react to produce the maximum amount of hydrogen gas, there will be 2.1 grams ( 1.1 moles) of hydrogen available to react with plutonium metal to form plutonium hydride. Using thermodynamic data from Flotow, Haschke, and Yamauchi, ${ }^{35}$ the heat of reaction for the formation of 1.1 moles of plutonium hydride $\left(\mathrm{PuH}_{2}\right)$ at $25^{\circ} \mathrm{C}$ is estimated as 178 kjoules (Appendix H).

The reaction rate of plutonium metal with hydrogen gas is dependent on several factors such as the contaminants on the plutonium metal surface or in the atmosphere (oxygen and moisture can have significant effects), the generation rate of the hydrogen gas, the partial pressure of hydrogen gas, and the temperature. The impact of that sensitivity to the reaction conditions has led to a wide variation in experimental results. Stiffler and Curtis found that without treatment of the plutonium metal surface, the hydriding reaction did not start until $50^{\circ} \mathrm{C} .^{36}$ It is expected that the $S S \& C$ plutonium metal surfaces will be contaminated with plutonium oxide by the time that hydrogen gas is generated and diffuses to the surface. Furthermore, based on the work by Haschke, Allen, and Stakebake, there will be a competing reaction for the hydrogen gas on the plutonium oxide surface, i.e., catalytic conversion to water. These factors will serve to reduce the rate of the hydriding reaction. As a result, the heat from the hydriding reaction is expected to be generated slowly.

A bounding case scenario for heat generation from the reaction of hydrogen gas with plutonium to form plutonium hydride can be developed. The worst case for hydrogen gas generation rate is from the reaction of calcium with water vapor. The calcium/water vapor reaction is expected to be complete within 10 hours at a reaction rate of 1.00 milligram $/ \mathrm{cm}^{2}$ hour (Section 2.3.1.1) with a water vapor pressure of 20 torr. If it is assumed that once the hydrogen gas is generated, it reacts immediately with plutonium to form plutonium hydride, then the hydriding reaction would occur within 10 hours with an average heat generation rate of about 5 watts. The containers would not have been placed into the 9975 Package within that time and heat would dissipate into the containers' storage environment. At a lower water vapor pressure, the reaction rate for the calcium/water vapor reaction is slower (Section 2.3.1.1). That reaction would be completed in 169 hours (about 7 days). For a seven-day reaction period, the average heat generation rate for the hydriding reaction would be 0.29 watts. That slower reaction also would be completed before the items are placed into the 9975 Package. If the hydriding reaction is slower than the calcium/water vapor reaction, then the heat generation rate from the hydriding reaction should not be a problem for the 9975 Package as it would be less than 0.29 watts.

Once plutonium hydride is generated, it will react with oxygen to form plutonium oxide. The hydrogen may be regenerated as hydrogen gas or the hydrogen atoms may be incorporated into the plutonium hydride matrix thus increasing the stoichiometric amount of hydrogen in the hydride. As the hydrogen gas is regenerated, it can react with plutonium metal to form more hydride. This generation of plutonium hydride can continue until the oxygen is consumed.

\subsubsection{Reactions at Higher Temperatures}

The 9975 Package provides excellent insulation for the SS\&C material. As a result, the SS\&C material will not equilibrate to the external temperature as its temperature increases due to radioactive decay. The bounding temperature for the 9975 Package is $107^{\circ} \mathrm{C}$. There is a concern that reaction rates at the higher

\footnotetext{
${ }^{35}$ H. E. Flotow, J. M. Haschke, and S. Yamauchi; The Chemical Thermodynamics of Actinide Elements and Compounds, Part 9 The Actinide Hydrides; International Atomic Energy Agency; Vienna, Austria; 1984.

${ }^{36}$ G. L. Stiffler and M. H. Curtis, The Preparation of Plutonium Powder by a Hydriding Process - Initial Studies, HW-64289, 1960.
} 
temperatures could lead to larger heat generation rates. Such increases in heat generation rates could increase the lemperature of the package beyond its bounding temperature or lead to pressurization of the container by the heated gases.

\subsubsection{Calcium Oxidation Reactions}

The calcium oxidation reactions at $107^{\circ} \mathrm{C}$ will not result in heat generation rates in excess of the 9975 Package limits. The rate of calcium oxidation in the presence of water vapor decreases as the temperature increases for temperatures less than $150^{\circ} \mathrm{C} .^{6}$ Therefore, the calcium oxidation rate analyzed in Section 2.3.1.1 is the bounding case for temperatures of interest to the 9975 Package SARP, i.e., temperatures up to $107^{\circ} \mathrm{C}$. As discussed in Section 2.3.1.2, the reaction of calcium oxide with water vapor and carbon dioxide is limited by the amount of carbon dioxide present in the 9975 Package. Even if the reaction rate increased as the temperature increased, that reaction is insignificant because there is so little carbon dioxide available to react. According to Nissen, the reaction rate of calcium with oxygen is constant below $300^{\circ} \mathrm{C}$ at $3 \times 10^{-3}$ milligrams $/ \mathrm{cm}^{2}$ hour. That case was analyzed in Section 2.3 .2 .1 .

\subsubsection{Plutonium/Water Vapor Reactions}

The plutonium/water vapor reaction rate at $107^{\circ} \mathrm{C}$ is expected to be substantially different from the rate at $25^{\circ} \mathrm{C}^{21}$ Haschke, Allen, and Stakebake derived an expression for the reaction rate as function of temperature:

$$
\text { Ln: } R=47.00-17320 / T
$$

With $R$ in units of millgrams $/ \mathrm{cm}^{2}$ hours. That derivation incorporated the equilibrium partial pressure of water vapor over condensed water. As such, that expression represents the most rapid moisture-enhanced rate for the reaction.

The first model used the following assumptions.

1. The 660 grams of plutonium was present as 1980 beads and each bead had a diameter of one-eighth inch.

2. The time for the 9975 Package to reach $107^{\circ} \mathrm{C}$ was ten days.

3. The rate of temperature increase was uniform for the ten days.

The rate constant was calculated at hour increments for a temperature increase of $21^{\circ} \mathrm{C}$ to $107^{\circ} \mathrm{C}$ over 10 days. With 1.1 moles of water vapor available for reaction, the reaction would be complete once the beads decrease in radius from $0.159 \mathrm{~cm}$ to $0.148 \mathrm{~cm}$. That reaction is completed after 7.2 days. The profile of the wattage is given in Figure 1, the maximum wattage associated with the reaction is about 4.2 watts and is attained at the end of the reaction. The temperature at that point is about $82^{\circ} \mathrm{C}$.

An improved model was developed in which a bead-size distribution was assumed. The distribution of bead sizes is reasonable because the pulverization and sieving process breaks up the SS\&C material into a range of sizes less than the quarter-inch diameter sieve. Such a distribution in radii would spread the reaction across a longer period of time, and thus, reduce the value of the heat generation rate. The 660 grams of plutonium were evenly divided among ten sets of beads. The initial radii of the bead sets were $0.310 \mathrm{~cm}, 0.159 \mathrm{~cm}, 0.080 \mathrm{~cm}, 0.040 \mathrm{~cm}, 0.020 \mathrm{~cm}, 0.010 \mathrm{~cm}, 0.005 \mathrm{~cm}, 0.0025 \mathrm{~cm}, 0.001 \mathrm{~cm}$, and $0.0005 \mathrm{~cm}$. The watt profile for the model with the distribution of bead radii is given in Figure 2. The water vapor is depleted after 4.3 days with a maximum heat generation rate of 3.4 watts. The temperature of the 9975 Package at the onset of the reaction is $58^{\circ} \mathrm{C}$. For the distribution of bead sizes, the heat generation rate in excess of 0.39 watts only lasts for two days before the water is exhausted.

A comparison of the watt profile for each model is given in Figure 3. The endpoint on the graph for each walt profile in represents the time at which the 0.55 moles of water have reacted completely. 
WSRC-TR-98-00311

September 22, 1998

Figure 1. Watt Profile for Model with $0.159 \mathrm{~cm}$ Radius Beads (The dashed line refers to the point at which the water is exhausted.)

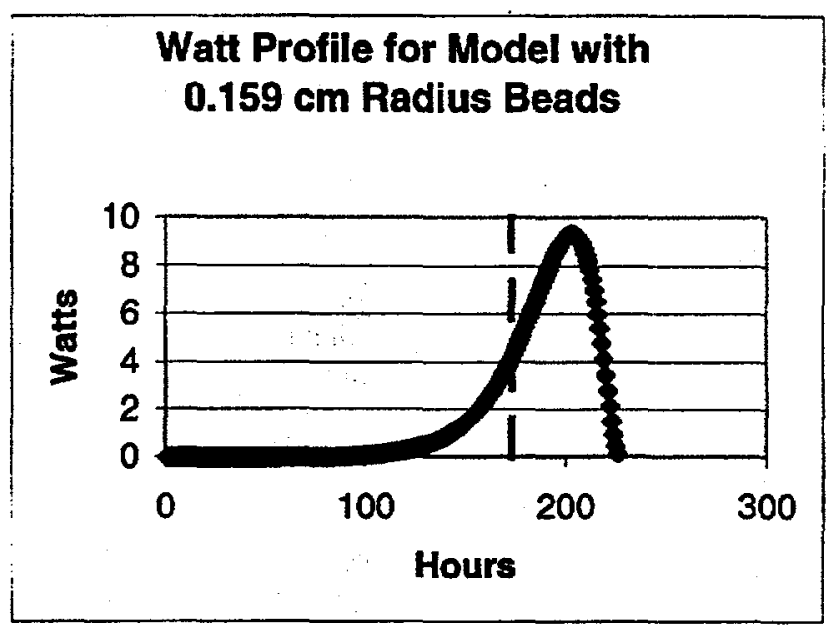

Figure 2. Watt Profile for Model with Distribution of Bead Radii (Dashed line indicates the point at which the water vapor is exhausted.)

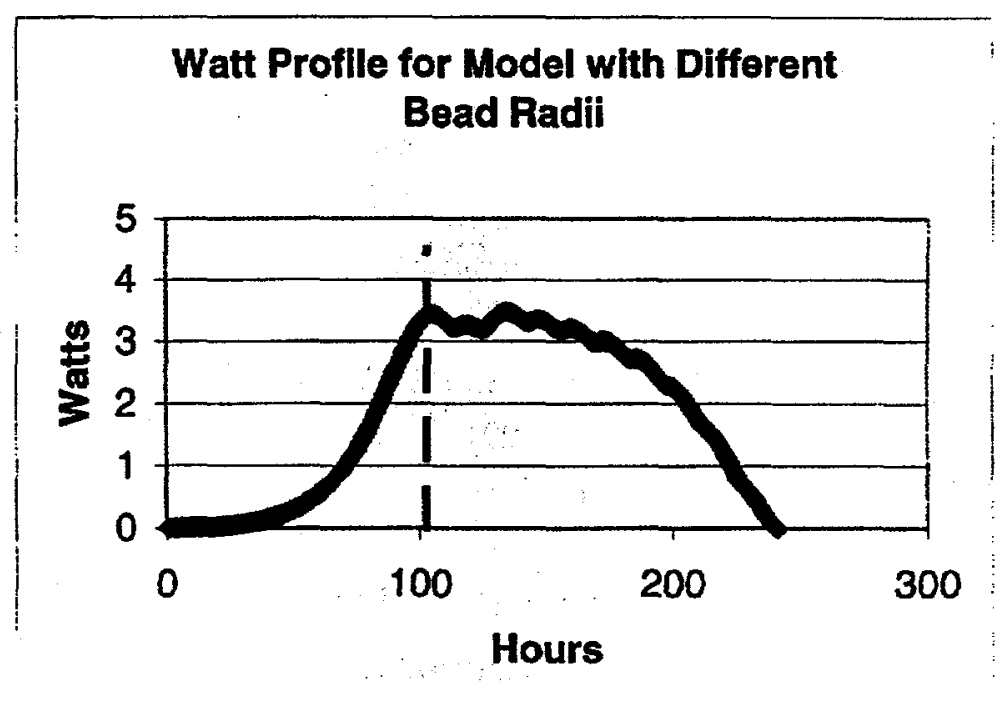


WSRC-TR-98-00311

September 22, 1998

Figure 3. Comparison of the Watt Profile for the Two Models (The endpoint indicates when the water vapor is depleted by the reaction.)

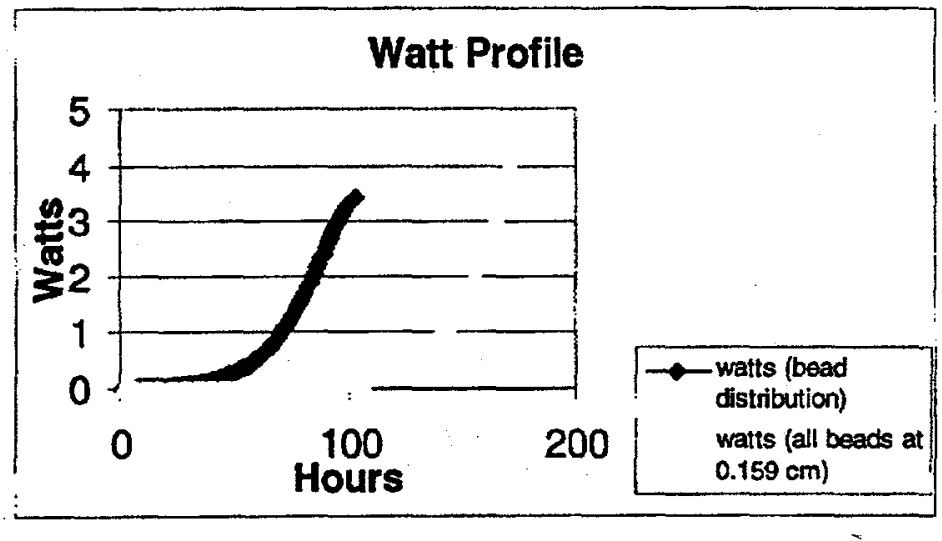

Both of these models are very conservative. For example. the models assume that all of the plutonium is present as the metal and that all of the metal is accessible by the water vapor. Any exposed plutonium metal in the SS\&C has been partially oxidized over the past 10 years and even more will oxidize during the pulverization and sieving operations at RFETS. Smaller plutonium pieces or beads may still be encapsulated in the slag material after pulverization and unavailable for reaction with water vapor. It is unlikely that all 660 grams of plutonium will be present as exposed metal.

The rate constant increases as a function of the vapor pressure of water. The Haschke, Allen, and Stakebake rate constant was derived using the equilibrium vapor pressure of water over condensed water. The water vapor in the 9975 Package will be in equilibrium with water adsorbed onto the surfaces of the SS\&C materials. Adsorption of water consists of two modes: physisorption and chemisorption. Both calcium fluoride and magnesium oxide adsorb water via the physisorption and chemisorption mechanisms (References in Section 2.3.1.1). Therefore, lower water vapor pressure is expected, and as a result, a lower rate of reaction is expected.

The RFETS DTA analyses are useful in allaying the concern about high temperature plutonium oxidation predicted by the models. Both models indicate that there should be a sharp rise in wattage as the reaction proceeds. For the single-radius bead model the temperature is at $82^{\circ} \mathrm{C}$ and for the bead distribution model the temperature is $58^{\circ} \mathrm{C}$. Of the 88 sampled SS\&C items, none of the DTA scans showed exotherms at temperatures below $85^{\circ} \mathrm{C}$. The DTA scans with an exotherm onset temperature less than or equal to $120^{\circ} \mathrm{C}$ are presented in Appendix $I^{37}$ As can be seen in a review of those scans, the onset temperature, as designated by the RFETS Solid Residue Characterization Program, is typically followed by a very slow increase in temperature, usually less than one degree Centigrade. Such behavior does not indicate that there will be any sharp increases in temperature or runaway chemical reactions within the allowable temperature regime of the 9975 Package much less near the calculated temperatures for the plutonium/water vapor reaction.

\footnotetext{
${ }^{37}$ The left $y$-axis represents the temperature ramp of the DTA instrument. That ramp is shown as a diagonal line from the lower-left corner to the upper-right corner on the graph. The right $y$-axis is the "Delta Temperature" between the sample and the standard. The DTA scan is represented by the curve that is in the center of the graph. Exothermic behavior is indicated by a positive "Delta Temperature", and endothermic behavior is shown by a negative "Delta Temperature".
} 
There is one DTA scan that shows pronounced activity immediately above $120 C^{\circ}$. That scan was obtained from a sample from Item CO5265 in the IDC 391 category (unpulverized sand and crucible). The exotherm profile is quite distinct from any of the other exotherms in Appendix I. Four other IDC 391 items were sampled as part of the RFETS Solid Residue Characterization Program. None of those DTA scans shows any similarity with the DTA scan from Item CO5265. Although $120^{\circ} \mathrm{C}$ is above the operating temperature of the 9975 Package, more information regarding the DTA scan of Item CO5265 has been requested from RFETS Solid Residue Characterization Program.

\subsubsection{Plutonium Hydrogen Gas Reactions}

The hydriding reaction will be limited by the availability of hydrogen gas. The worst case is for the hydrogen produced by the plutonium/water vapor reaction. Assuming a similar reaction rate, the hydriding would occur over the 4.3 days with an average heat generation rate of 0.26 watts.

\section{RFETS Fluoride Residues}

\subsection{Description}

There are five categories of RFETS fluoride residues:

IDC 090 Plutonium Tetrafluoride

IDC 091 Non-specification Plutonium Tetrafluoride

IDC 092 Impure Fluoride Heel

IDC 093 Sodium Fluoride Pellets

IDC 097 Impure Fluoride "Heel" in Small Inner Cans.

There is a neutron radiation dose associated with the fluoride residues. The reaction of the fluorine nuclei with the plutonium alpha particles leads to the emission of neutrons, i.e., alpha-neutron reactions. With the exception of the IDC 092 material, the fluoride material is considered relatively inert with respect to chemical reactions. The IDC 092 material may contain moisture and residual nitrates; those constituents may lead to corrosive reactions with the containment vessel. The fluoride residues will be calcined prior to shipment to SRS to remove water and residual nitrates from the fluoride residues.

In contrast to the SS\&C residues, every fluoride item is individually identified. Table 2 shows the plutonium distribution in the fluoride residues.

Table 2. Plutonium Distribution in Fluoride Residues

\begin{tabular}{|c|c|c|c|c|c|}
\hline IDC & 090 & 091 & 092 & 093 & 097 \\
\hline Total $\mathrm{Kg}$ in IDC & 2.5 & 185 & 41 & 71 & 18 \\
\hline $\mathrm{Kg}$ with $<10$ wt\% Pu & & 16 & & 22 & 17.8 \\
\hline $\begin{array}{l}\mathrm{Kg} \text { with } \\
10-<25 \text { wt } \% \mathrm{Pu}\end{array}$ & & 4 & 15 & 27 & 0.2 \\
\hline $\begin{array}{l}\mathrm{Kg} \text { with } \\
25-<4 \theta \text { wt\% } \mathrm{Pu}\end{array}$ & & 9 & 6 & 9 & \\
\hline $\begin{array}{l}\mathrm{Kg} \text { with } \\
40-<55 \text { wt\% } \mathrm{Pu}\end{array}$ & & 17. & 14 & & \\
\hline $\begin{array}{l}\mathrm{Kg} \text { with } \\
55-<70 \text { wt\% } \mathrm{Pu}\end{array}$ & & 98 & 5 & & \\
\hline Kg with $>70$ wt $\% \mathrm{Pu}$ & 2.5 & 41 & 1. & 13 & \\
\hline
\end{tabular}

\subsection{Plutonium Tetrafluoride}

The first two categories (IDCs 090 and 091) were the product of the hydrofluorination process at RFETS in which plutonium oxide was converted to plutonium tetrafluoride (often referred to as "pink cake" at RFETS). The plutonium tetrafluoride subsequently was converted to plutonium metal in the bomb reduction process. 
WSRC-TR-98-00311

September 22, 1998

\subsubsection{Pure Plutonium Tetrafluoride - IDC 090}

Pure plutonium tetrafluoride (i.e., material that met the specifications for purity) was designated as IDC 090. There are only about 2.5 kilograms of IDC 090 at RFETS. As part of the RFETS Residue Characterization Program, four IDC 090 items were sampled. The $x$-ray diffraction analyses identified plutonium tetrafluoride and plutonium oxide. ${ }^{38}$ With the exception of some tests done to determine if this material should be considered as mixed hazardous waste, there were no other analyses done.

\subsubsection{Impure Plutonium Tetrafluoride - IDC 091}

The remaining plutonium tetrafluoride (IDC 091) material did not meet the purity specifications. Impurities could be as small as a few parts per million or as large as several percent. The impurities might be from stainless-steel contamination (e.g., chromium, iron, and nickel), aluminum, silicon, or other undesirable elements. Typically, the impure plutonium tetrafluoride was dissolved in Building 771 to produce a plutonium product that did meet the purity specifications. There are about 185 kilograms of IDC 091. Pure plutonium tetrafluoride is about $76 \%$ plutonium by weight.

Bight IDC 091 items were sampled for the RFETS Solid Residue Characterization Program. In addition to plutonium tetrafluoride and plutonium oxide, the $x$-ray diffraction analyses identified sodium bifluoride $\left(\mathrm{NaHF}_{2}\right)$, sodium fluoride $(\mathrm{NaF})$, and double salts of plutonium tetrafluoride with sodium fluoride (e.g., $\mathrm{Na}_{2} \mathrm{PuF}_{6}$ ) as the main constituents. ${ }^{39}$

The $x$-ray diffraction analysis of one item did show potassium chloride. That item is not typical of the IDC 091 material. It only has 1 weight\% plutonium. With so little plutonium, it is difficult to regard the material as merely impure plutonium tetrafluoride. The item was generated in May 1987; there was no production processing of chlorides in Building 771 after 1980 . Its identification number (07700618) does not fit with the normal identification numbers of the IDC 091 material: $07061 \times x x$. The sampling records from the RFETS Solid Residue Characterization Program show that the material was generated in Building . 771, Glovebox Line 21C. That glovebox line was used to treat solutions from the analytical laboratories. Potassium fluoride was added to the solutions to precipitate the plutonium as plutonium trifluoride. The precipitated fluoride was sent to the Building 771 dissolution glovebox line to recover and purify the plutonium. Based on the identification of Item 07700618 as IDC 091, it appears that all residues from Glovebox Line $21 \mathrm{C}$ were designated as IDC 091 inaterials. There are four other IDC 091 items with identification numbers like $07700 \mathrm{xxx}$. Those items should be carefully scrutinized by RFETS prior to inclusion in the shipment to SRS because it is likely that those materials are not impure plutonium tetrafluoride.

As part of the RFETS Solid Residue Characterization Program, the contact radiation dose was measured for each sampled package that was not stored in the Building 371 S/R Vault. The contact radiation dose was measured for seven IDC 091 items. All of those items had contact radiation doses $<200 \mathrm{mREM} /$ hour. The contact radiation dose readings are given in Table 3 .

With the exception of some tests done to determine if this material should be considered as mixed hazardous waste, there were no other analyses done.

$$
\text { Ax }
$$

\footnotetext{
${ }^{38}$ The initial report on the $x$-ray diffraction results stated that calcium fluoride was present in those items. Upon further consultation with the X-ray diffraction analyst at Los Alamos National Laboratory (Otis Peterson, e-mail July 6, 1998), the calcium fluoride assignment was dismissed because the identification was so tenuous and there is no process knowledge to justify its presence in the IDC 090 material. The plutonium assay alone indicates that only plutonium compounds are present. And to be considered as IDC 090 material, a sample of the material had to be analyzed to demonstrate that it met the processing specifications.

${ }^{39}$ The initial report on the x-ray diffraction results stated that several chlorides were in the sampled IDC 091 items. Upon further consultation with the $x$-ray diffraction analyst at Los Alamos National Laboratory (Otis Peterson, e-mail September 2, 1998), the most of the chloride assignments were dismissed.
} 
WSRC-TR-98-00311

September 22, 1998

Table 3. Contact Radiation Dose Measurements for Sampled IDC 091 Items

\begin{tabular}{|l|l|l|l|}
\hline $\begin{array}{l}\text { Item } \\
\text { Identification }\end{array}$ & $\begin{array}{l}\text { Plutonium } \\
\text { Content } \\
\text { (grams/wt \%) }\end{array}$ & $\begin{array}{l}\text { Gamma } \\
\text { Radiation } \\
\text { (mREM/hour) }\end{array}$ & $\begin{array}{l}\text { Neutron } \\
\text { Radiation } \\
\text { (mREM/hour) }\end{array}$ \\
\hline 07061163 & $773 / 61$ & 53 & 120 \\
\hline 07061174 & $893 / 70$ & 43 & 120 \\
\hline 07061187 & $490 / 50$ & 43 & 80 \\
\hline 07061222 & $886 / 61$ & 35 & 61 \\
\hline 07061252 & $1145 / 70$ & 52 & 84 \\
\hline 07242186 & $295 / 19$ & 32 & 40 \\
\hline 07700618 & $4 / 1$ & 6 & 4 \\
\hline
\end{tabular}

\subsubsection{Fluoride Heel - IDC 092}

Impure plutonium tetrafluoride was dissolved to recover and purify the plutonium. Aluminum nitrate was added to the nitric acid solution to assist with the dissolution of the plutonium tetrafluoride. The dissolution process still was not completely effective and a heel often remained. That heel was collected after filtration and was dried. The dried heel was stored in anticipation of future processing for plutonium recovery. There are about 41 kilograms of IDC 092.

The x-ray diffraction analyses of ten IDC 092 items identified a variety of trashy compounds that are expected in calcined material. Those compounds include plutonium oxide, silicon oxide, calcium fluoride, aluminum fluoride, plutonium tetrafluoride, and plutonium trifluoride. The contact radiation dose was measured on tive of the sampled IDC 092 items. None of the measured dose rates exceeded 200 $\mathrm{mREM} / \mathrm{hour}$. The weight loss at $105^{\circ} \mathrm{C}$ was measured for five items. That measurement was used to gauge the moisture content. The weight losses ranged from 0.34 weight\% to 1.25 weight\%. The observations that were noted during the sampling for the IDC 092 items were reviewed. The Subject Matter Expert (SME) in charge of the sampling made the following observations. Of the ten IDC 092 items that were sampled, the SME noted corroded or rusted cans for seven of the items. Problems were noted for both the inside and outside of the can holding the IDC 092 material. Most of the cans were identified as 1-liter, stainless steel, slip-lid containers that were commonly used at RFETS for packaging material. Such corrosion is probably due to incomplete drying of the heel material prior to its packaging.

With the exception of some tests done to determine if this material should be considered as mixed hazardous waste, there were no other analyses done.

\subsection{Sodium Fuoride Pellets $\mathbf{0 9 3}$}

Sodium fluoride pellets were used to adsorb the plutonium hexafluoride offgas from the fluidized bed fluorination process in Building 371. There are about 71 kilograms of the sodium fluoride pellet residues (IDC 093).

There is an internal Rocky Flats Plant report (Chem R\&D 84-016) that discusses the proposed dissolution flow sheet for the IDC 093 residues. ${ }^{40}$ The report also describes the residue as a mixture of pink and gray pellets. The $x$-ray diffraction analysis of the gray pellets identified $\mathrm{NaHF}_{2}$ as the major constituent. According to the report, the sodium bifluoride forms as a result of the adsorption of hydrogen fluoride (used in the fluorination process) by the $\mathrm{NaF}$ pellets. Minor constituents in the gray pellets were sodium fluoride and the sodium fluoride: plutonium tetrafluoride double salt. The $x$-ray analysis of the pink pellets identified sodium fluoride as the primary constituent with trace amounts of the sodium fluoride: plutonium tetrafluoride double salt.

\footnotetext{
${ }^{40}$ A. R. Kazanjian. and J. R. Stevens, Dissolution of Sodium Fluoride Residue, Internal Rocky Flats Plant Report: Chem R\&D 84-016, April 9, 1984.
} 
The initial report of recent $x$-ray diffraction analyses did not agree completely with the previous analyses. Of the eight IDC 093 items sampled, only one showed the sodium bifluoride compound (sodium fluoride also was identified). The other analyses showed plutonium oxide, sodium fluoride, calcium fluoride, sodium nitrate, and sodium oxide. Consultation with the LANL analyst resulted in a revision of the $x$-ray diffraction report. ${ }^{41}$ That revised report is in agreement with the RFP report. Sodium fluoride, sodium bifluoride, the sodium fluoride: plutonium tetrafluoride double salt, and plutonium oxide are the identified constituents. Sodium nitrate and sodium oxide were deleted as constituents.

The weight loss at $105^{\circ} \mathrm{C}$ was measured for nine items. That measurement was used to gauge the moisture content. The weight losses ranged from 0.44 weight $\%$ to 1.04 weight\%.

With the exception of some tests done to determine if this material should be considered as mixed hazardous waste, there were no other analyses done.

\subsection{IDC 097}

The source of the IDC 097 material is not well established. Initial descriptions state that the IDC 097 material is similar to IDC 091 but it is packaged in smaller cans. However, a recent review of the plutonium concentration in the IDC 097 material brought that description into doubt. The average plutonium concentration in IDC 097 is only about 6. weight\%. Furthermore, not only is IDC 097 a much leaner category with respect to plutonium concentration compared to IDC 091, but the two IDC categories have completely different plutonium distribution profiles. That review led to the designation of the IDC 097 material as fluoride-heel material, i.e., material similar to IDC 092 . However, a comparison of the plutonium distribution between IDC 092 and IDC 097 materials show that those two IDCs are not similar either.

A comparison of the SME observations and of the analytical data from the sampling shows further dissimilarity between IDCs 092 and 097 . The $x$-ray diffraction profile of the IDC 097 items is quite distinct from the IDC 092 items. In fact, there seem to be two subpopulations of the IDC 097 material based on the $x$-ray diffraction. A review of the SME observations of the IDC 097 substantiates the existence of two subpopulations in IDC 097.

\subsubsection{IDC 097 - Subpopulation 1}

Five of the eight items sampled for IDC 097 belong to this subpopulation.

The chemical constituents in this material are the same as in the IDC 093 material. The identified compounds in the initial $x$-ray diffraction report were predominantly sodium fluoride, sodium nitrate, and a sodium fluoride: plutonium tetrafluoride double salt. Consultation with the LANL analyst led to the identification of sodium bifluoride instead of sodium nitrate in this subpopulation of the IDC 097 material. ${ }^{42}$ Thus, the three major chemical constituents (sodium fluoride, sodium bifluoride, sodium fuoride: plutonium tetrafluoride double salt) are the same as reported for the IDC 093 material.

The SME observations note that this material is a pink powder:

The weight loss at $105^{\circ} \mathrm{C}$ was measured for two of the items in this subpopulation. The weight loss for each item was 0.77 weight $\%$.

With the exception of some tests done to determine if this material should be considered as mixed hazardous waste, there were no other analyses done.

\footnotetext{
41 Otis Peterson, e-mail June 16. 1998.
}

42 Otis Peterson, e-mail June 23, 1998. 


\subsubsection{IDC 097. Subpopulation 2}

Three of the eight items sampled for IDC 097 belong to this subpopulation.

The $x$-ray diffraction analyses show that the material is amorphous with some traces of plutonium oxide. The SME observations note that this material is reddish-brown or cocoa or coffee colored. One SME noted the presence of nuts, bolts, and brush bristles in these items. It is possible that this subpopulation is calcined glovebox sweepings. This material is very distinct from the other IDC 097 subpopulation.

The weight loss at $105^{\circ} \mathrm{C}$ was measured for one of the items in this subpopulation. The weight loss was 3.04 weight\%.

With the exception of some tests done to determine if this material should be considered as mixed hazardous waste, there were no other analyses done. Two of these items showed the presence of cadmium; neither the other IDC 097 subpopulation nor the material in IDC 092 showed cadmium. 
Appendix A

Table A1. Heats of Reaction for CalciumWater Reaction at Several Temperatures $\mathrm{Ca}+2 \mathrm{H} 2 \mathrm{O}$ (vapor) $=\mathrm{Ca}(\mathrm{OH}) 2+\mathrm{H} 2$

Material Heat of $H(T)-H(T)-H(T)-H(T)-H(T)-$

Formation $\mathrm{H}(298 \mathrm{~K}) \mathrm{H}(298 \mathrm{~K}) \mathrm{H}(298 \mathrm{~K}) \mathrm{H}(298 \mathrm{~K}) \mathrm{H}(298 \mathrm{~K})$ $298 \mathrm{~K} \quad 27 \mathrm{C} \quad 77 \mathrm{C} \quad 93 \mathrm{C} \quad 121 \mathrm{C} \quad 127 \mathrm{C}$

$\begin{array}{lllllll}(\mathrm{kJ} / \mathrm{mol}) & (\mathrm{kJ} / \mathrm{mol}) \quad(\mathrm{kJ} / \mathrm{mol}) & (\mathrm{kJ} / \mathrm{mol}) & (\mathrm{kJ} / \mathrm{mol}) & (\mathrm{kJ} / \mathrm{mol})\end{array}$

\begin{tabular}{|c|c|c|c|c|c|c|}
\hline $\mathrm{Ca}$ & 0 & 0.048 & 1.354 & 1.77928 & 2.52352 & 2.683 \\
\hline $\mathrm{H} 2 \mathrm{O}$ (liq) & -285.83 & 0.139 & 3.9085 & 5.10974 & & \\
\hline H2O (vap) & -241.826 & 0.062 & 1.757 & 2.2994 & 3.2486 & 3.452 \\
\hline $\mathrm{Ca}(\mathrm{OH}) 2$ & -986.085 & 0.162 & 4.8485 & 6.34818 & 8.97262 & 9.535 \\
\hline $\mathrm{H} 2$ & 0 & 0.053 & 1.502 & 1.96824 & 2.78416 & 2.959 \\
\hline $\begin{array}{l}\text { Enthaipy } \\
\text { of } \\
\text { Reaction }\end{array}$ & -502.433 & -502.39 & -500.951 & $\begin{array}{r}-500.495 \\
\end{array}$ & -500.104 & -499.526 \\
\hline $\begin{array}{l}\text { Heat from } \\
\text { Change in } \\
\text { gas moles }\end{array}$ & $\begin{array}{r}-2.47769 \\
\end{array}$ & -2.49432 & -2.91004 & -3.04307 & -3.276 & -3.326 \\
\hline
\end{tabular}

$\begin{array}{lllllll}\text { Heat of } & -499.955 & -499.896 & -498.04 & -497.452 & -496.828 & -496.2\end{array}$

Reaction

( $\mathrm{kJ} / \mathrm{mole}$ of Calcium) 
Appendix B

Calculations for One-Eighth Inch Diameter Beads

The average diameter of the calcium and plutonium beads in the SS\&C residues is assumed to be oneeighth inch diameter. That assumption is based on the SS\&C pulverization and sieving that will be done at RFETS prior to shipment to SRS. The sieving will allow a maximum of one-quarter inch diameter material into the package.

$D_{0}=0.125$ inches

$\mathrm{R}_{0}=0.0625$ inches $=0.159 \mathrm{~cm}(@ 2.54 \mathrm{~cm} / \mathrm{inch})$

Surface area $=4 \pi \mathrm{ro}_{0}^{2}=0.318 \mathrm{~cm}^{2}$

Volume $=(4 / 3) \pi \mathrm{r}_{0}^{3}=0.0168 \mathrm{~cm}^{3}$

For calcium beads:

1.55 grams $/ \mathrm{cm}^{3}=$ density of calcium

Density $\times$ volume/bead $=$ mass $/$ bead

$1.55 \mathrm{grams} / \mathrm{cm}^{3} \times 0.0168 \mathrm{~cm}^{3} /$ bead $=0.0260 \mathrm{grams} / \mathrm{bead}$

105 grams of calcium/container at 5 weight\% calcium in 2.1 kilograms of SS\&C material

$105 \mathrm{grams} /(0.0260 \mathrm{grams} / \mathrm{bead})=4,040$ beads of calcium in one container

In two containers there would be 8,080 beads of calcium.

For plutonium beads:

$19.84 \mathrm{grams} / \mathrm{cm}^{3}=$ density of plutonium

Density $\mathrm{x}$ volume/bead $=$ mass/bead

$19.84 \mathrm{grams} / \mathrm{cm}^{3} \times 0.0168 \mathrm{~cm}^{3} /$ bead $=0.334 \mathrm{grams} /$ bead

Maximum 330 grams of plutonium/container

330 grams $/(0.333$ grams $/$ bead $)=991$ beads of plutonium in one container

In two containers there would be 1,980 beads of plutonium. 
Appendix C

Model for Reaction Times

The reaction rate is function of mass and time. For a reaction rate constant $k$ and a surface area $A$, the change in mass with respect to the change in time is given by:$$
-k A=(d m / d t) \text {. }
$$

If the material is assumed to be spheres, both the surface area and the mass can be written in terms of the radius of the sphere.

$$
\begin{gathered}
A=4 \pi r^{2} \\
m=\text { density } \times \text { volume } \\
m=\rho(4 / 3) \pi r^{3}
\end{gathered}
$$

The expression for the reaction rate can be rewritten as:

$$
\begin{gathered}
-k 4 \pi r^{2}=d\left(\rho(4 / 3) \pi r^{3}\right) / d t \\
-k 4 \pi r^{2}=\rho(4 / 3) \pi\left[d\left(r^{3}\right) / d t\right] \\
-k 4 \pi r^{2}=\rho 4 \pi r^{2} d r / d t .
\end{gathered}
$$

Canceling out common factors and rearranging yields the expression:

$$
-k=\rho d r / d t .
$$

Integrating the expression from time $=0$ and radius $=r_{0}$ to time $=t$ and radius $=r$ gives:

$$
-k t=\rho\left(r-r_{0}\right) \text {. }
$$

The time for $a_{i}$ specific change in the radius is:

$$
t=\rho\left(r-r_{0}\right) / k \text {. }
$$


Appendix D

Table D1. Heats of Reaction for Calcium Oxide/Water Reaction at Several Temperature! $\mathrm{CaO}+\mathrm{H} 2 \mathrm{O}=\mathrm{Ca}(\mathrm{OH}) 2$

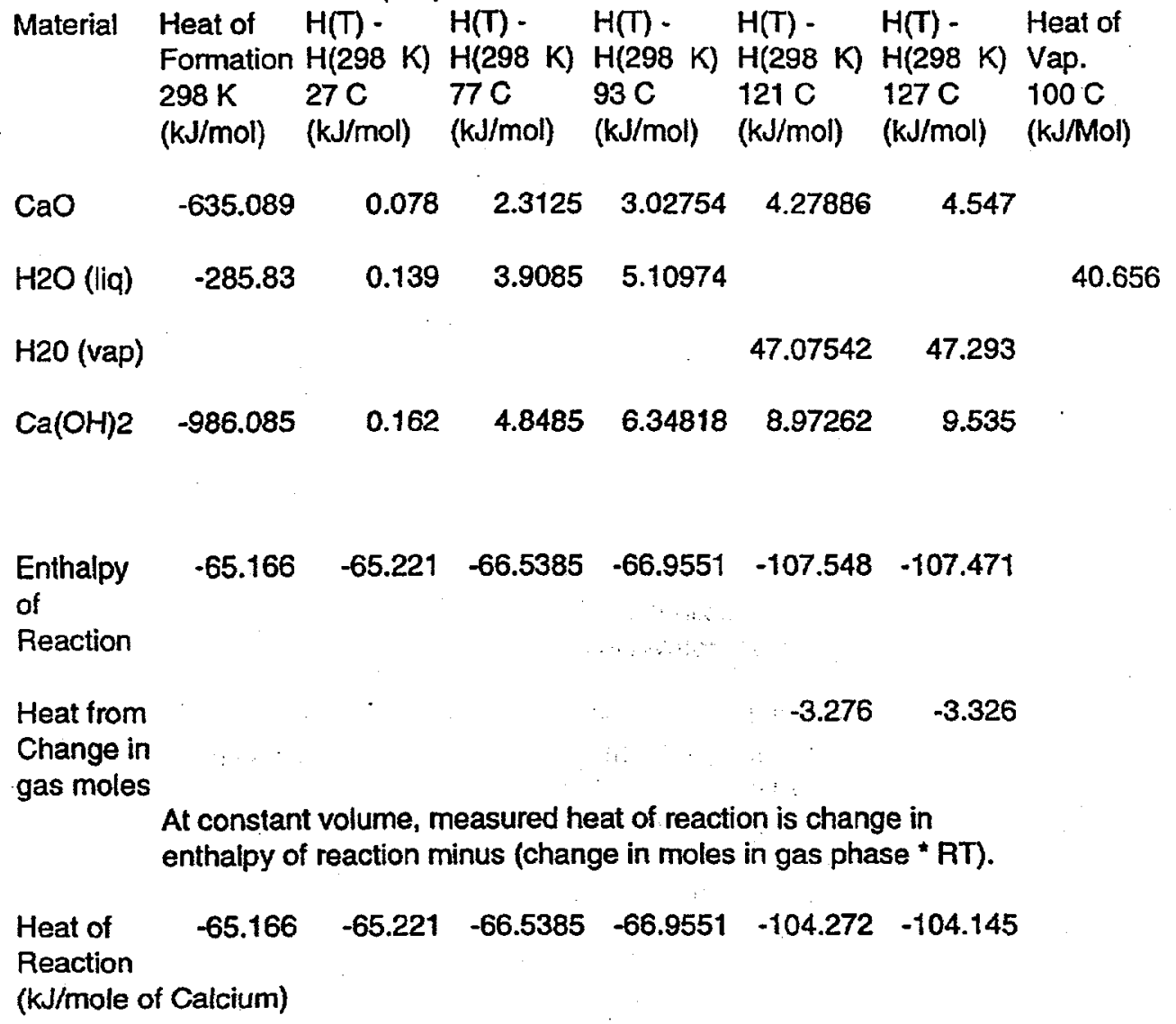


WSRC-TR-98-00311

September 22, 1998

Appendix $E$

Table E1. Heats of Reaction for Plutonium Water Vapor Reaction at Several Temperatur $\mathrm{Pu}+2 \mathrm{H} 2 \mathrm{O}$ (vapor) $=\mathrm{PuO} 2+2 \mathrm{H} 2$

Material Heat of $H(T)-H(T)-H(T)-H(T)-H(T) \cdot \quad$ Heat of Formation $\mathrm{H}(298 \mathrm{~K}) \mathrm{H}(298 \mathrm{~K}) \mathrm{H}(298 \mathrm{~K}) \mathrm{H}(298 \mathrm{~K}) \mathrm{H}(298 \mathrm{~K})$ Vap. $298 \mathrm{~K} \quad 27 \mathrm{C} \quad 77 \mathrm{C} \quad 93 \mathrm{C} \quad 121 \mathrm{C} \quad 127 \mathrm{C} \quad 100 \mathrm{C}$ $\begin{array}{llllllll}(\mathrm{kJ} / \mathrm{mol}) & (\mathrm{kJ} / \mathrm{mol}) & (\mathrm{kJ} / \mathrm{mol}) & (\mathrm{kJ} / \mathrm{mol}) & (\mathrm{kJ} / \mathrm{mol}) & (\mathrm{kJ} / \mathrm{mol}) & (\mathrm{kJ} / \mathrm{Mol})\end{array}$

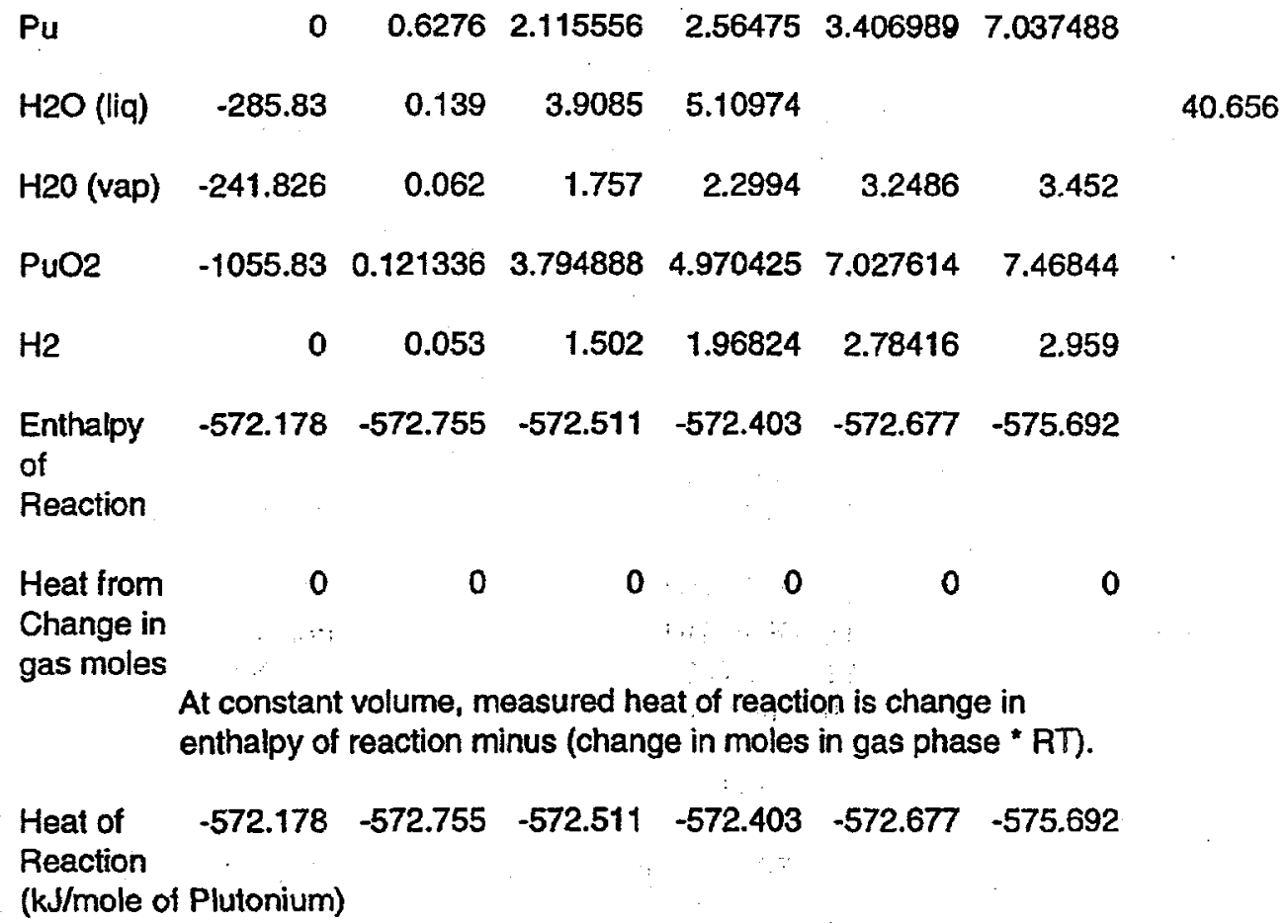


Appendix F

Table F1. Heats of Reaction for Calcium/Oxygen Reaction at Several Temperatures $2 \mathrm{Ca}+\mathrm{O} 2=2 \mathrm{CaO}$

$\begin{array}{llllll}\text { Material } & \text { Heat of } H(T)- & H(T)- & H(T)- & H(T)- & H(T)- \\ & \text { Formation } H(298 K) & H(298 K) & H(298 K) & H(298 K) & H(298 K)\end{array}$ $298 \mathrm{~K} \quad 27 \mathrm{C} \quad 77 \mathrm{C} \quad 93 \mathrm{C} \quad 121 \mathrm{C} \quad 127 \mathrm{C}$

$\begin{array}{lllllll}(\mathrm{kJ} / \mathrm{mol}) & (\mathrm{kJ} / \mathrm{mol}) & (\mathrm{kJ} / \mathrm{mol}) & (\mathrm{kJ} / \mathrm{mol}) & (\mathrm{kJ} / \mathrm{mol}) & (\mathrm{kJ} / \mathrm{mol})\end{array}$

$\begin{array}{lrlllll}\mathrm{Ca} & 0 & 0.048 & 1.354 & 1.77928 & 2.52352 & 2.683 \\ \mathrm{O} 2 & 0 & 0.054 & 1.531 & 2.00908 & 2.84572 & 3.025 \\ \mathrm{CaO} & -635.089 & 0.078 & 2.3125 & 3.02754 & 4.27886 & 4.547\end{array}$

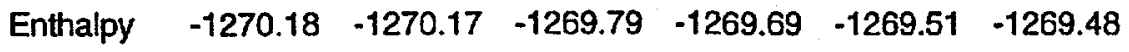

of

Reaction

$\begin{array}{lllllll}\text { Heat from } & -2.47769 & -2.49432 & -2.91004 & -3.04307 & -3.27587 & -3.32576\end{array}$

Change in

gas moles

At constant volume, measured heat of reaction is change in

enthalpy of reaction minus (change in moles in gas phase * RT).

$\begin{array}{lllllll}\text { Heat of } & -633.85 & -633.839 & -633.441 & -633.324 & -633.119 & -633.075\end{array}$

Reaction

(kJ/mole of Calcium) 
Appendix $\mathrm{G}$

Table G1. Heats of Reaction for Plutonium/Oxygen Reaction at Several Temperatures $\mathrm{Pu}+02=\mathrm{PuO} 2$

Material Heat of $H(T)-H(T)-H(T)-H(T)-H(T)$ Formation $H(298 K) H(298 K) H(298 K) H(298 K) H(298 K)$ $\begin{array}{llllll}298 \mathrm{~K} & 27 \mathrm{C} & 77 \mathrm{C} & 93 \mathrm{C} & 121 \mathrm{C} & 127 \mathrm{C}\end{array}$ $\begin{array}{llllll}(\mathrm{kJ} / \mathrm{mol}) & (\mathrm{kJ} / \mathrm{mol}) & (\mathrm{kJ} / \mathrm{mol}) & (\mathrm{kJ} / \mathrm{mol}) & (\mathrm{kJ} / \mathrm{mol}) & (\mathrm{kJ} / \mathrm{mol})\end{array}$

$\mathrm{Pu}$ $\begin{array}{llllll}0 & 0.6276 & 2.115556 & 2.56475 & 3.406989 & 7.037488\end{array}$

$\mathrm{O} 2$

$$
\begin{array}{llllll}
0 & 0.054 & 1.531 & 2.00908 & 2.84572 & 3.025
\end{array}
$$

$\begin{array}{lllllll}\text { PuO2 } & -1055.83 & 0.121336 & 3.794888 & 4.970425 & 7.027614 & 7.46844\end{array}$

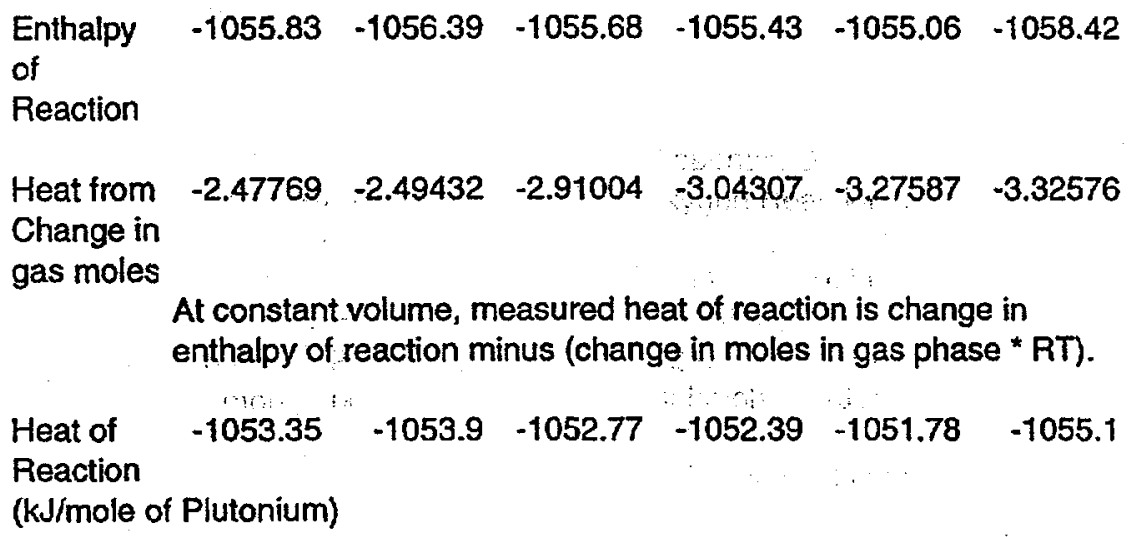


Appendix $\mathrm{H}$

Table H1. Heats of Reaction for Plutonium/Hydrogen Reaction at Several Temperatures $\mathrm{Pu}+\mathrm{H} 2=\mathrm{PuH} 2$

Material Heat of $H(T)$ -

Formation $\mathrm{H}(298 \mathrm{~K}) \mathrm{H}$

$H(T) \cdot$

$H(T) \cdot$

$H(T)-$

$H(T)-$

Heat of

$298 \mathrm{~K}$

$27 \mathrm{C}$

$77 \mathrm{C}$

$H(298$
$93 \mathrm{C}$

$\mathrm{H}(298 \mathrm{~K})$

$121 \mathrm{C}$

K) $\mathrm{H}(298 \mathrm{~K})$ Vap.

$(\mathrm{kJ} / \mathrm{mol}) \quad(\mathrm{kJ} / \mathrm{mol})$

$(\mathrm{kJ} / \mathrm{mol}) \quad(\mathrm{kJ} / \mathrm{mol})$

$100 \mathrm{C}$

$0 \quad 0.6276$

$\begin{array}{llll}2.115556 & 2.56475 & 3.406989 & 7.037488\end{array}$

Pu

0

0.053

$1.502 \quad 1.96824$

2.78416

2.959

$\mathrm{PuH} 2$

$-164.431$

0.081

2.5485

3.3381

4.7199

5.016

Enthalpy

$-164.431-165.031$

$-165.5-165.626$

$-165.902 \quad-169.411$

Reaction

Heat from

$\begin{array}{llllll}-2.47769 & -2.49432 & -2.91004 & -3.04307 & -3.27587 & -3.32576\end{array}$

Change in

gas moles

At constant volume, measured heat of reaction is change in enthalpy of reaction minus (change in moles in gas phase * RT).

Heat of $\begin{array}{llllll}-161.953 & -162.536 & -162.59 & -162.583 & -162.626 & -166.086\end{array}$

Reaction

( $\mathrm{kJ} /$ mole of Plutonium) 
WSRC-TR-98-00311

September 22, 1998

\section{Appendix I}

DTA Scans from

RFETS Solid Residue Characterization Program 


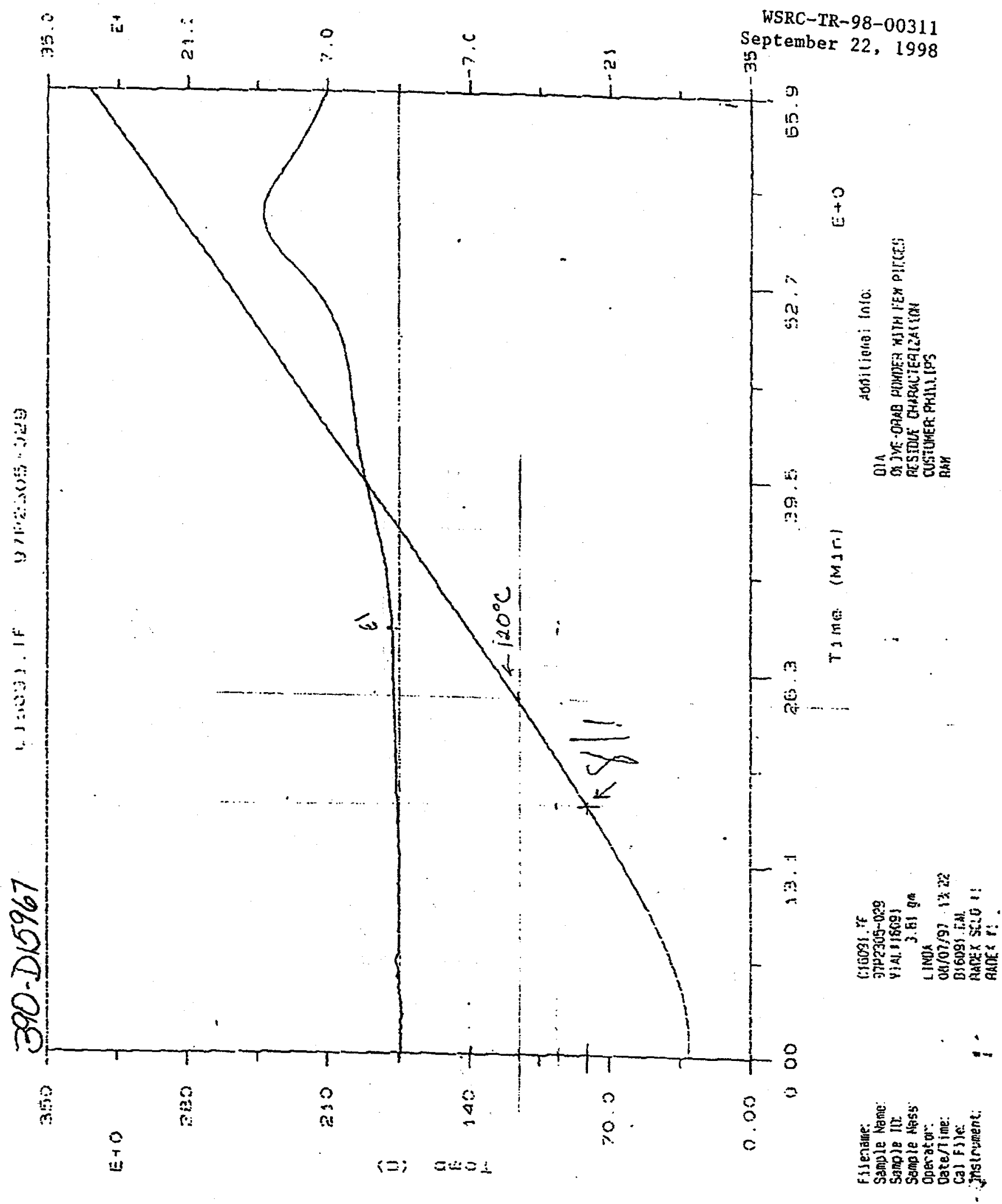




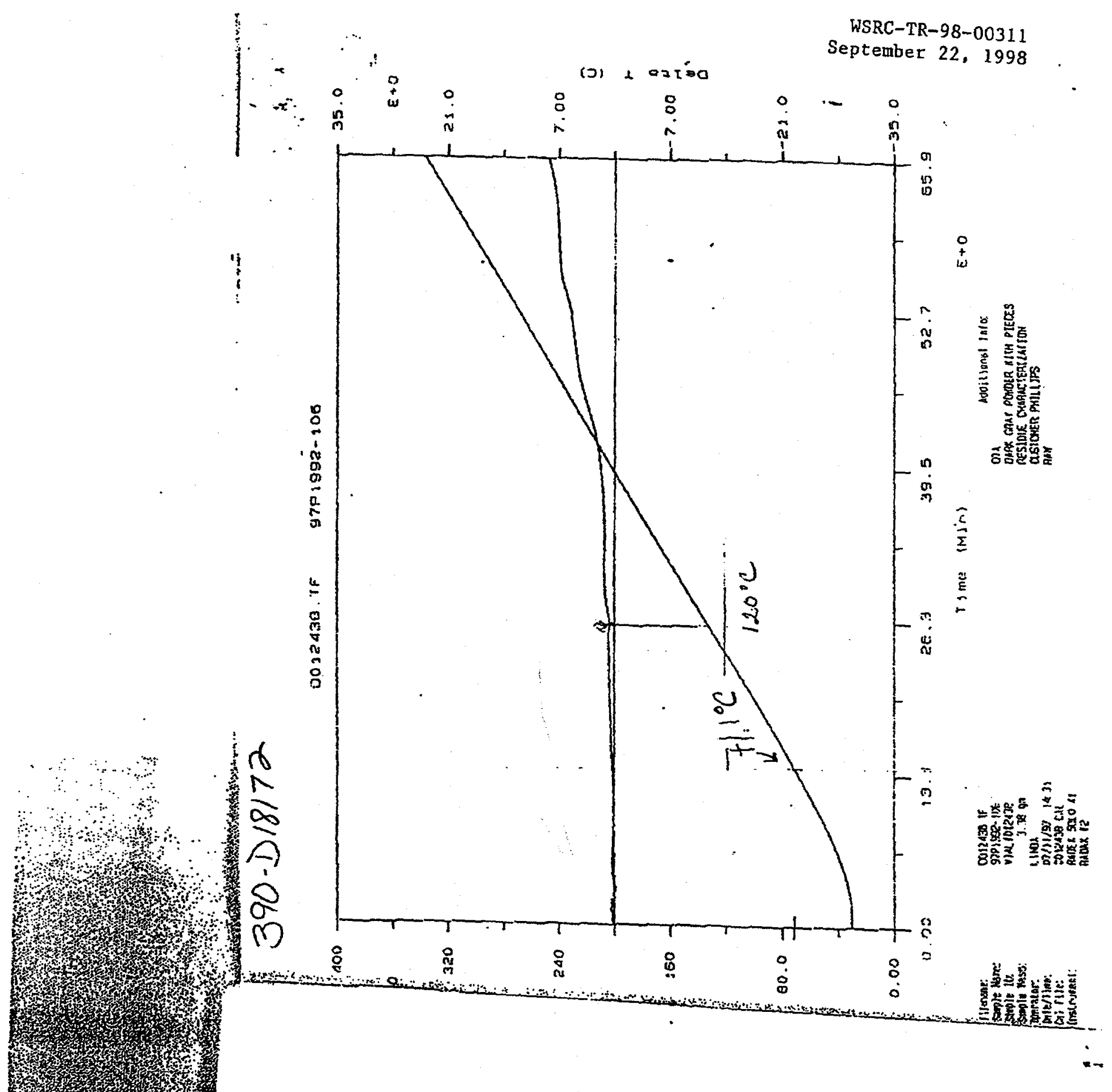


WSRC-TR-98-00311

September 22, 1998

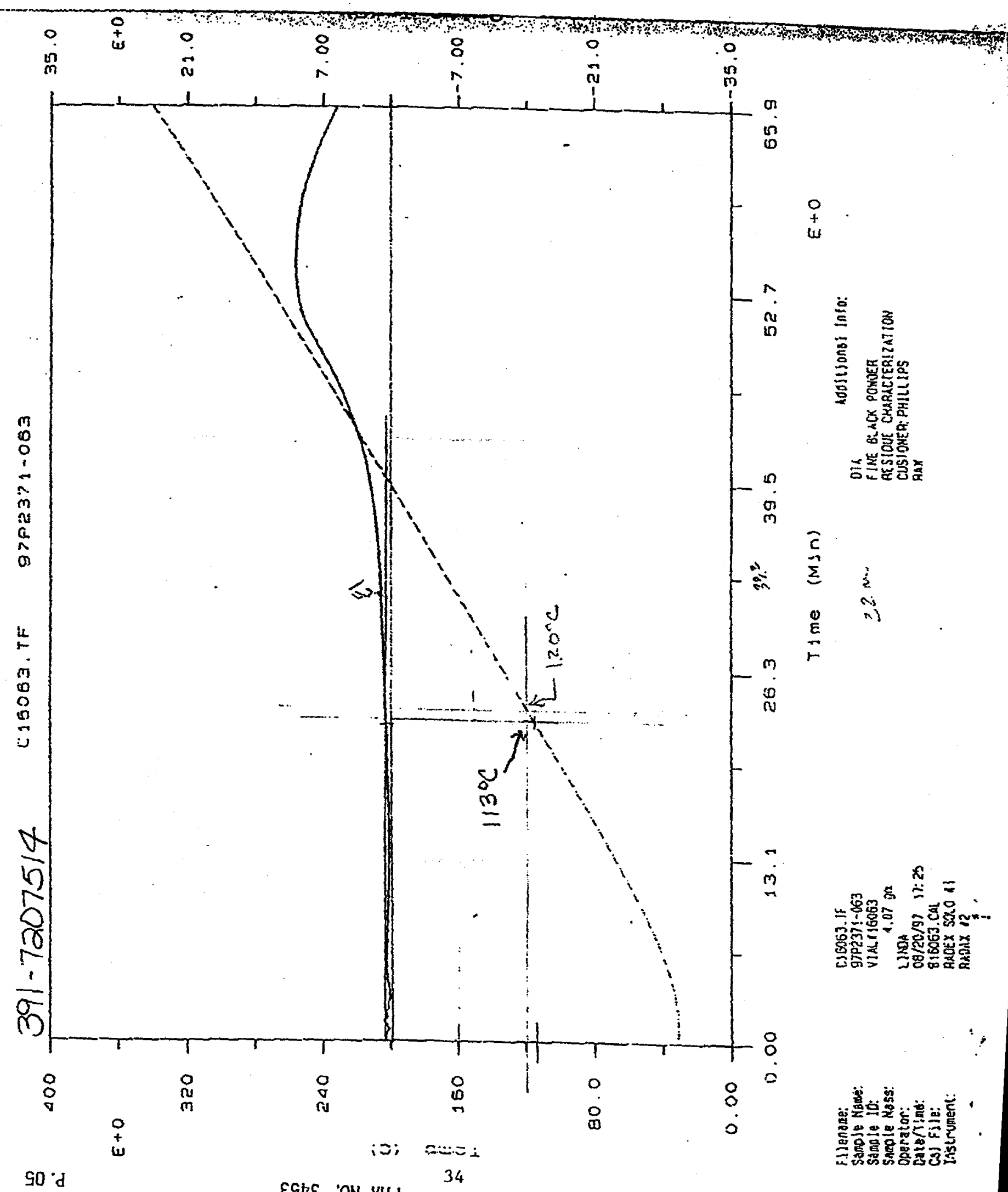


WSRC-TR-98-00311

September 22, 1998
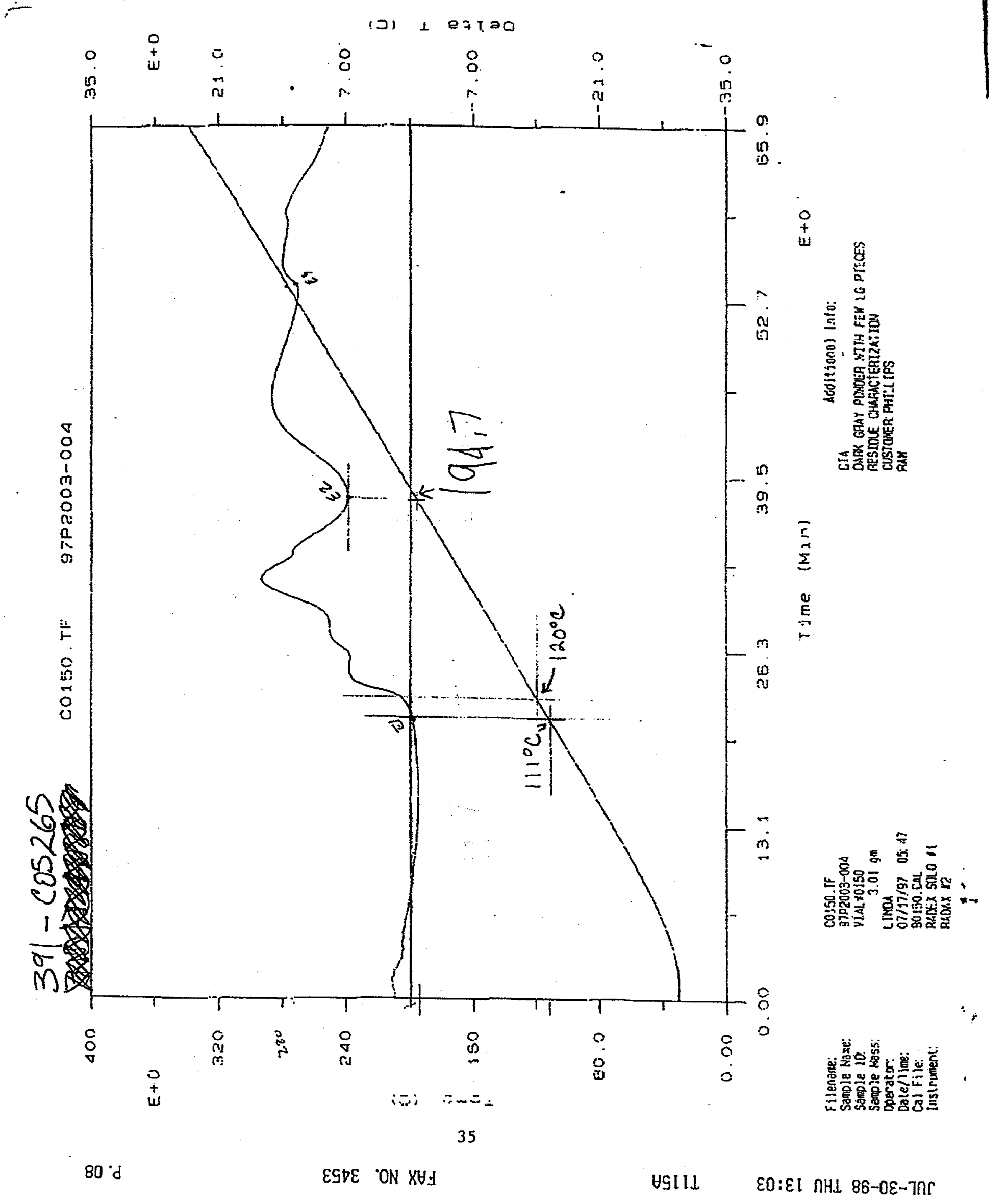
WSRC-TR-98-00311

September 22, 1998

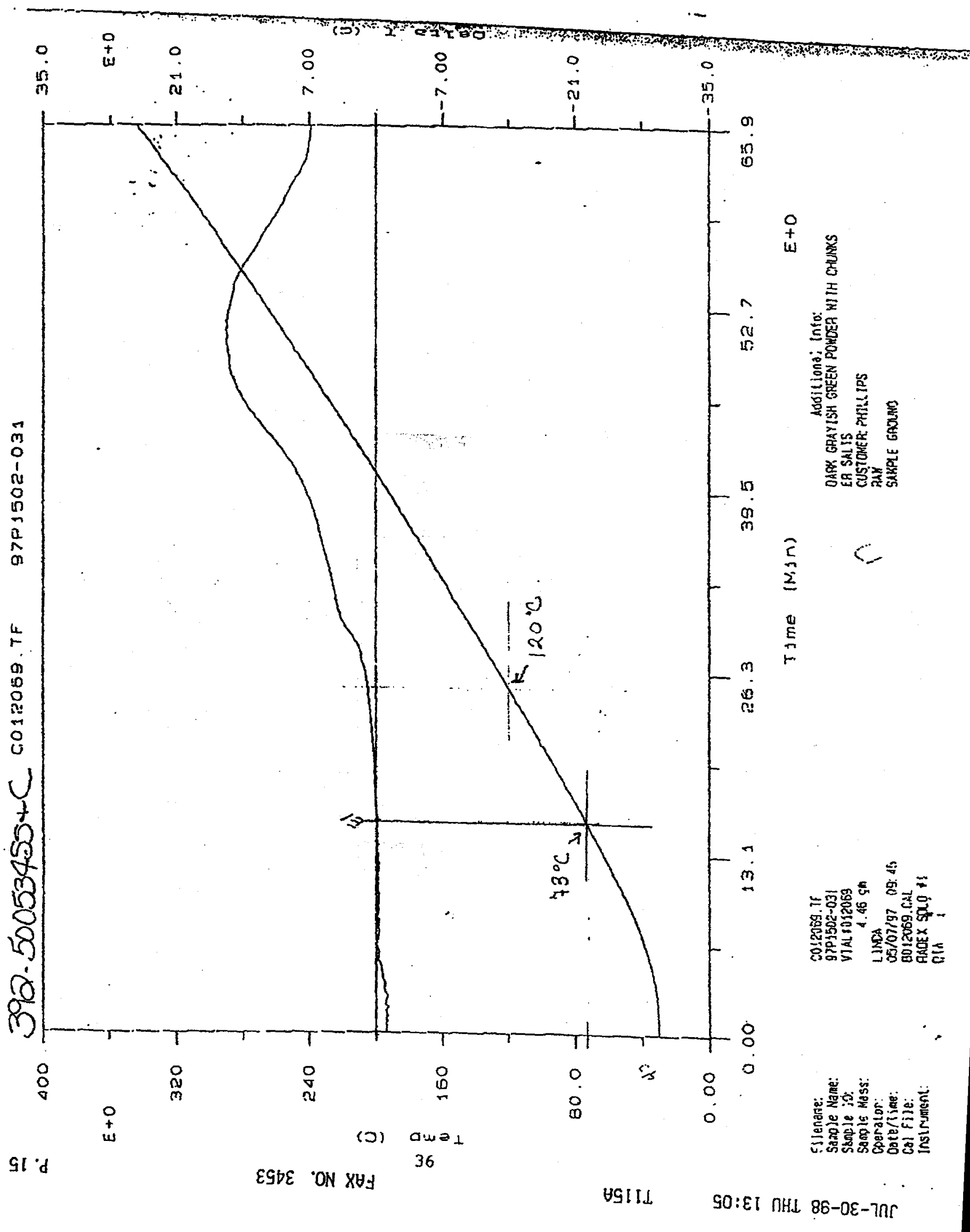


WSRC-TR-98-00311

September 22, 1998

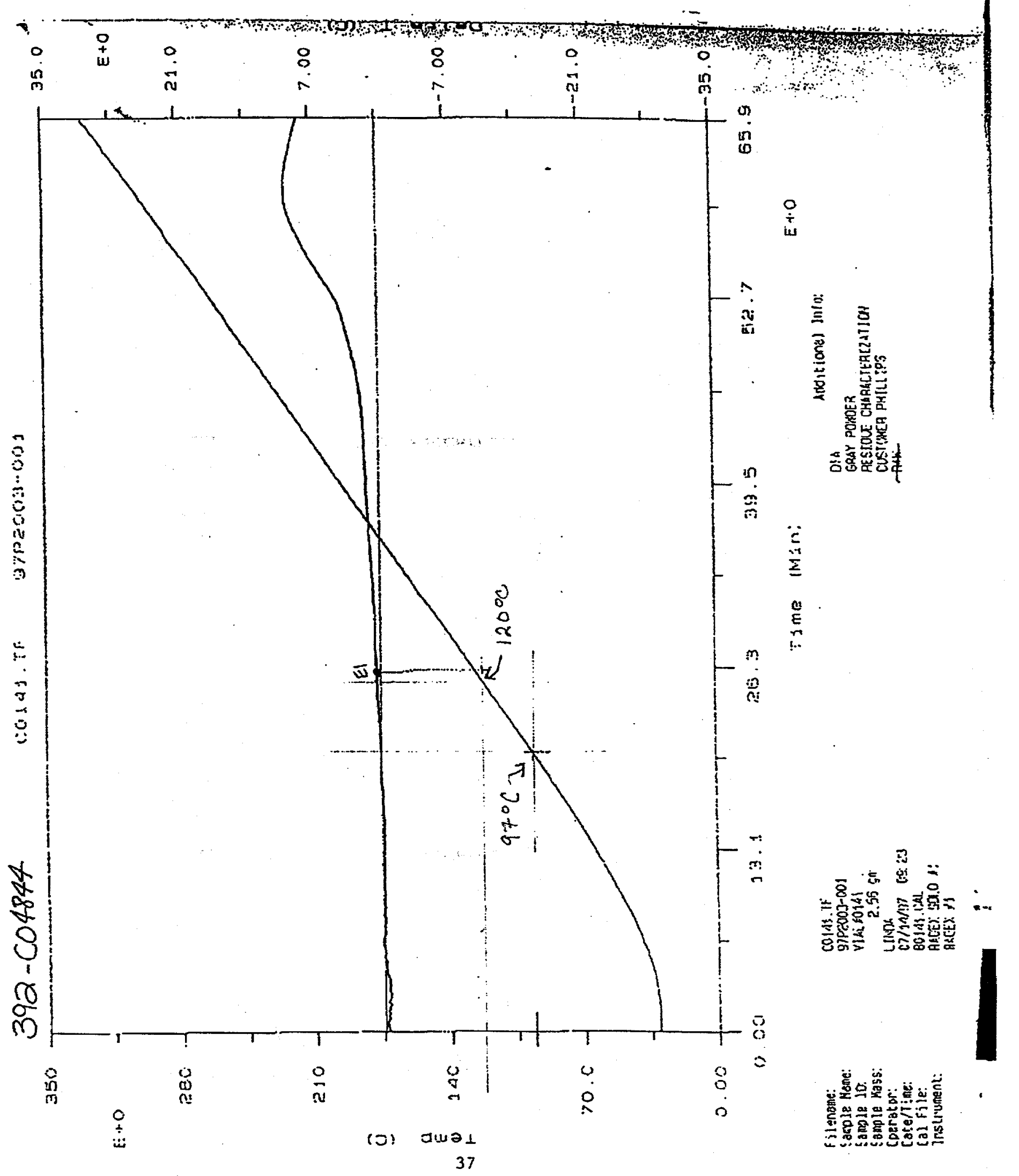


WSRC-TR-98-00311

September 22, 1998

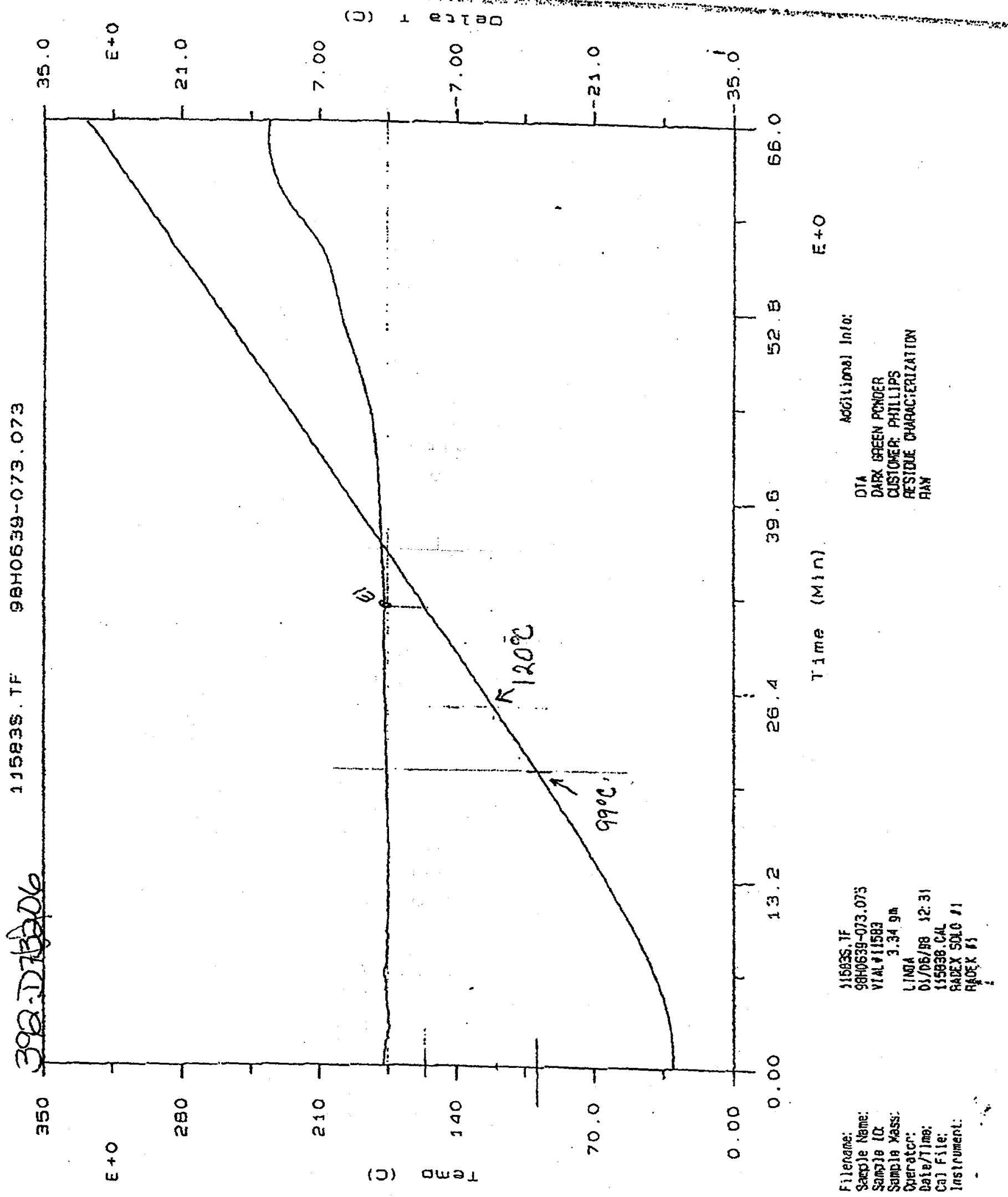


SRC-TR-98-00311

September 22, 1998

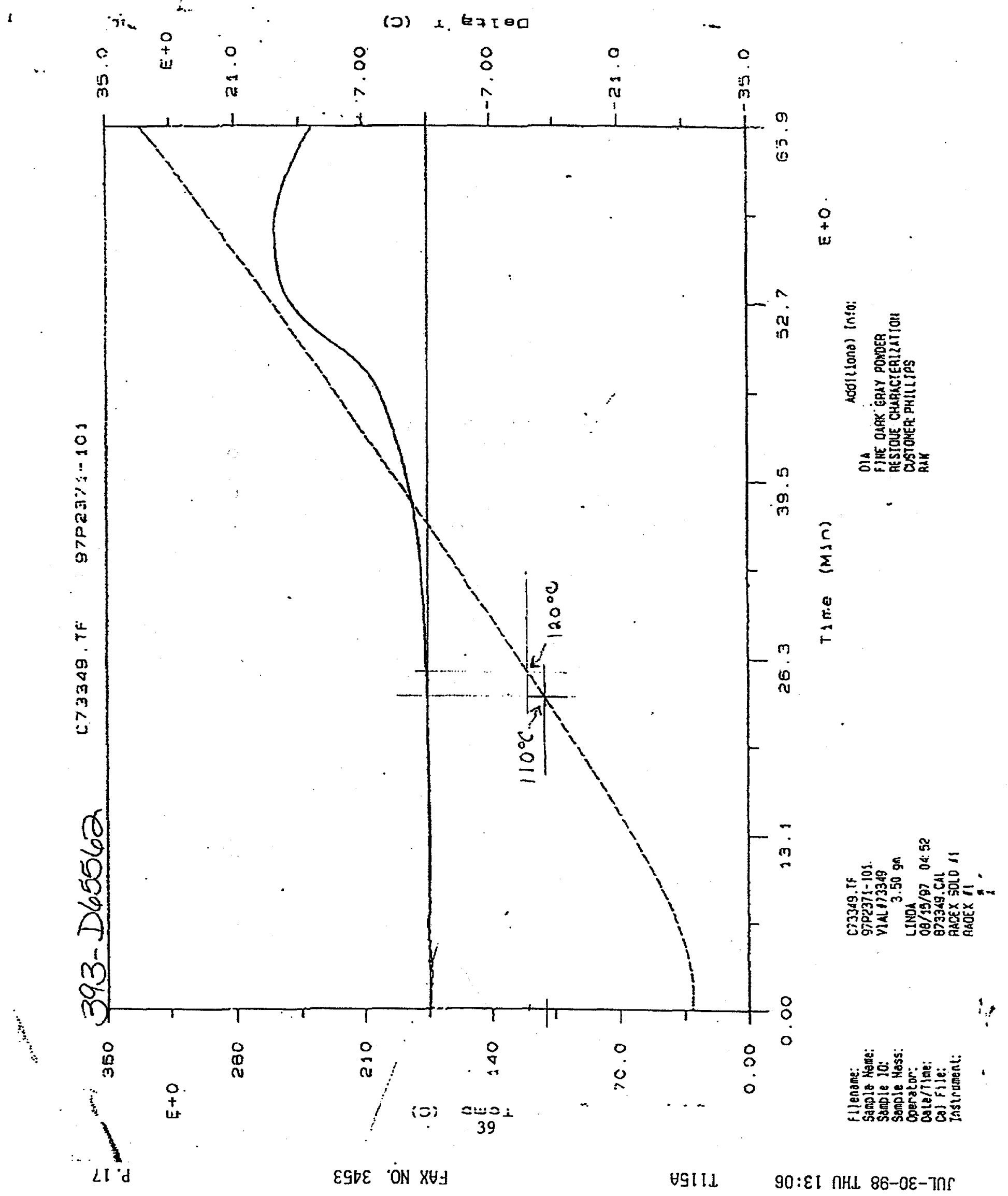


WSRC-TR-98-00311

September 22, 1998

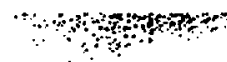

$\vdots$

$\therefore$

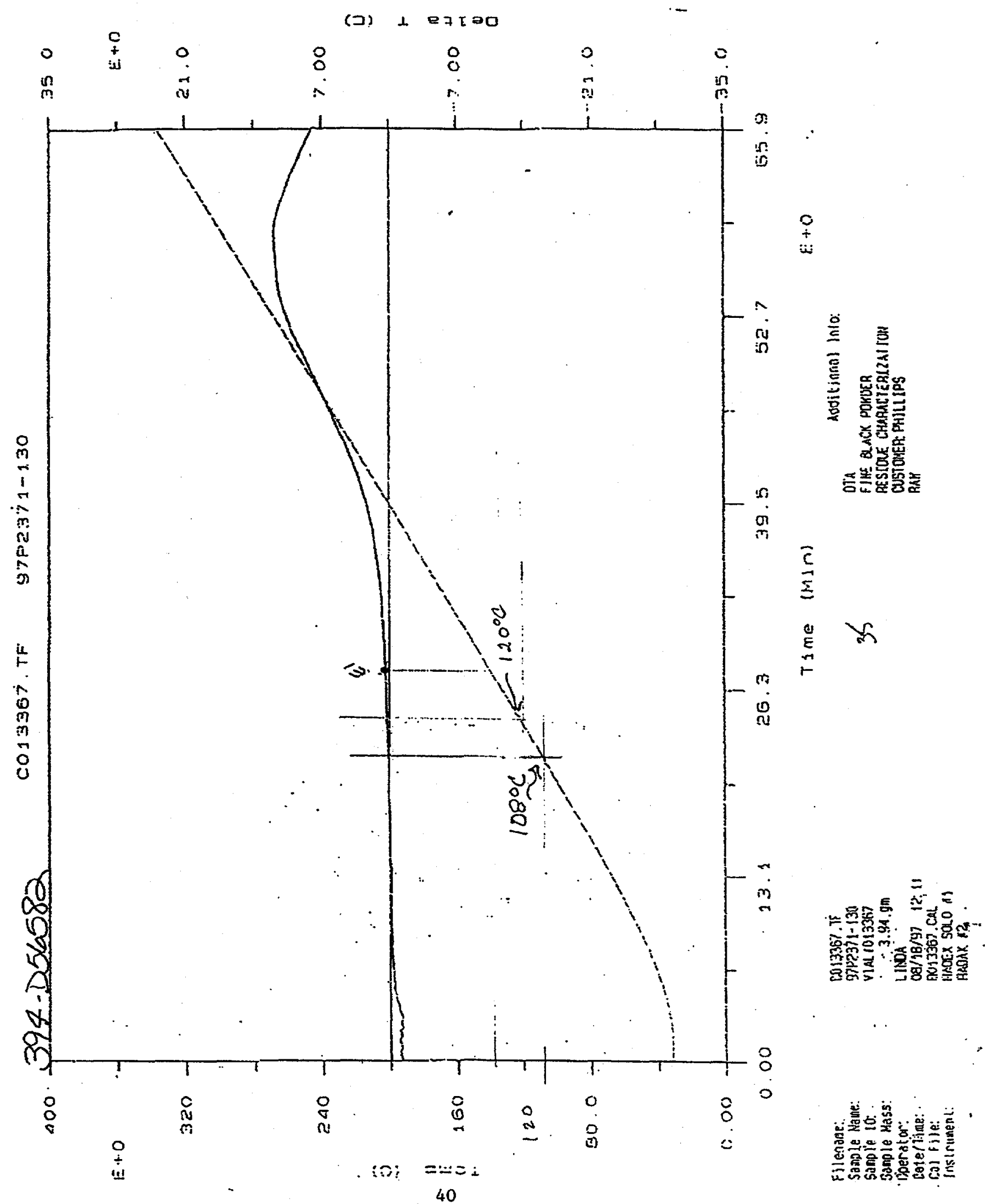

$\varepsilon z \cdot d$

ESDE ON XUA

YGIIL

$80: \varepsilon$ I กHL 86-0E-Tก 
WSRC-TR-98-00311

September 22, 1998

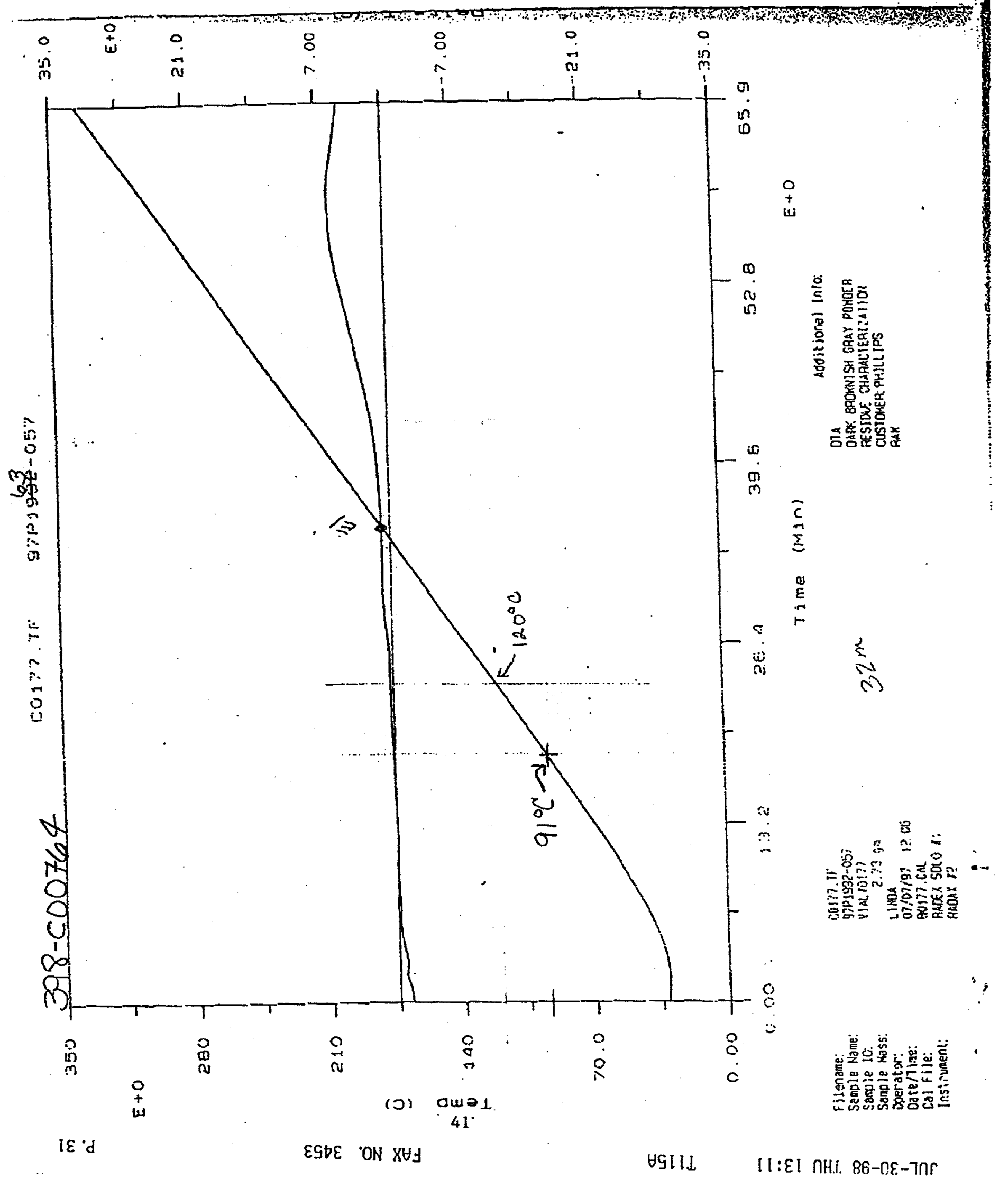


WSRC-TR-98-00311

September 22, 1998

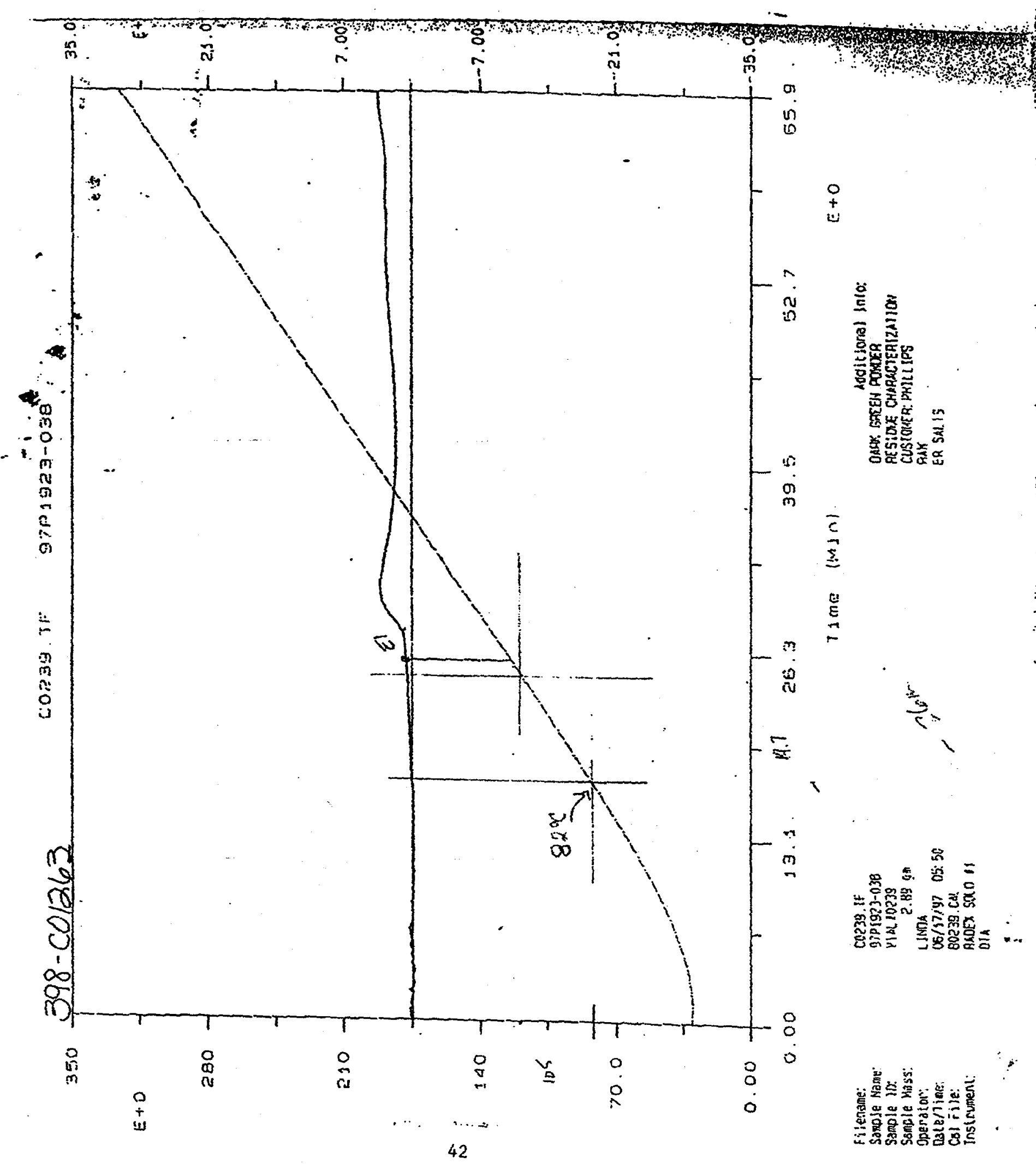

$a \varepsilon^{\prime d}$ 
WSRC-TR-98-00311

September 22, 1998

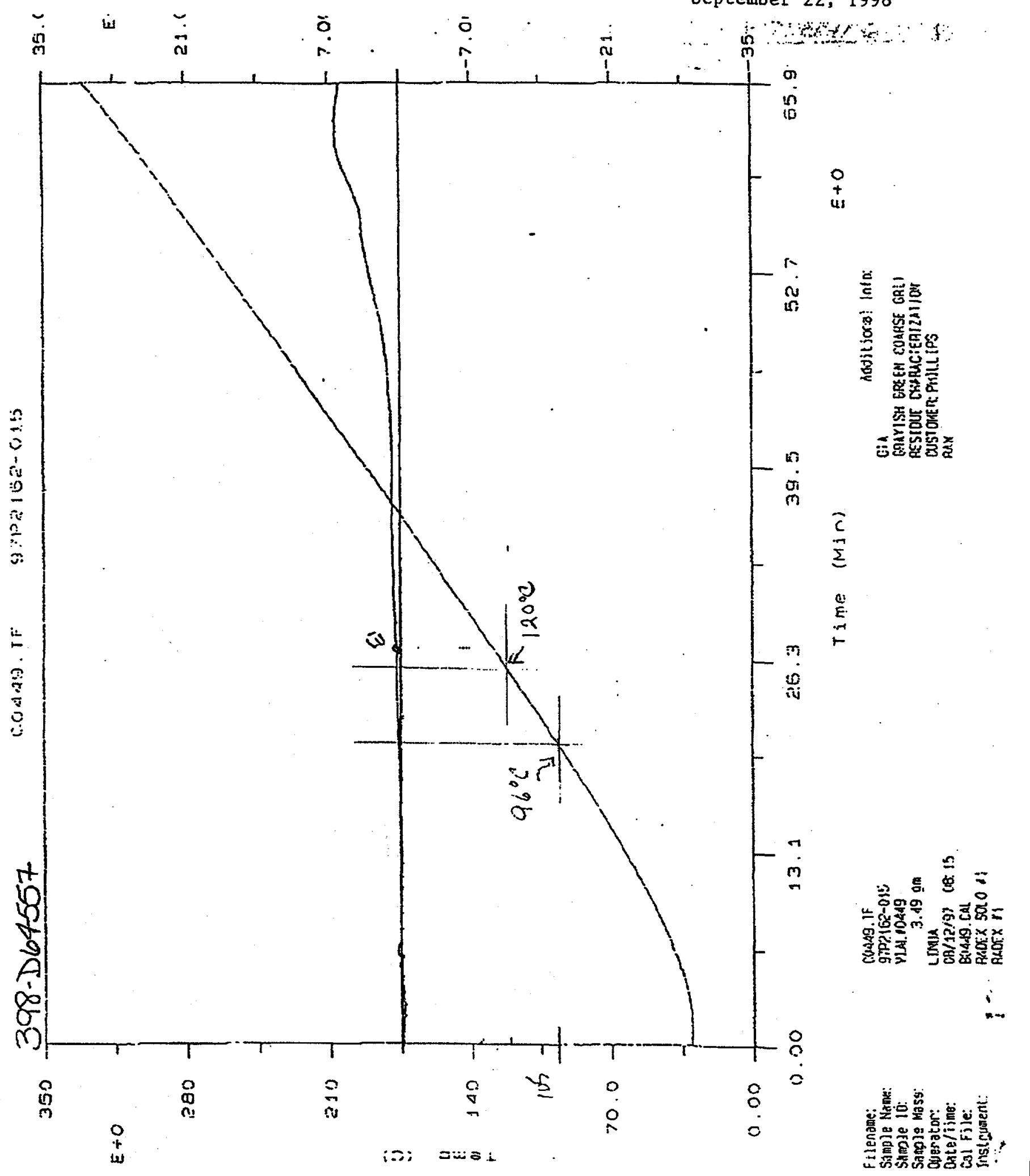

43

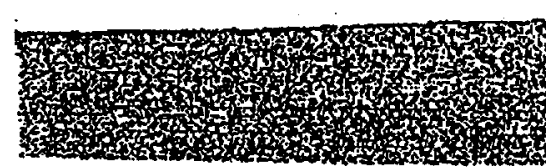

$62 \cdot d$

ES๑E ON XUI

$\forall G I$ I.L

$0 I: \varepsilon I \cap H\rfloor, 86-0 \varepsilon-7 \cap \Gamma$ 
M. L. Crowder

F. R. Graham

R. J. Gromada

T. C. Hasty

S. J. Hensel

M. E. Hodges

T. K. Houghtaling

R. R. Livingston

W. M. Massey

E. K. Opperman

J. B. Schaade

M. N. Van Alstine

P. R. Vormelker

SRTC Records, 773-52A \\ WSRC Internal Distribution}

